Illinois State University

ISU ReD: Research and eData

Theses and Dissertations

6-20-2018

\title{
The Effect of Concept Mapping on Baccalaureate Nursing Students' Knowledge Acquisition
}

Pamela S. Laskowski

Illinois State University, plaskowski@millikin.edu

Follow this and additional works at: https://ir.library.illinoisstate.edu/etd

Part of the Higher Education Administration Commons, Higher Education and Teaching Commons, and the Nursing Commons

\section{Recommended Citation}

Laskowski, Pamela S., "The Effect of Concept Mapping on Baccalaureate Nursing Students' Knowledge Acquisition" (2018). Theses and Dissertations. 988.

https://ir.library.illinoisstate.edu/etd/988

This Dissertation is brought to you for free and open access by ISU ReD: Research and eData. It has been accepted for inclusion in Theses and Dissertations by an authorized administrator of ISU ReD: Research and eData. For more information, please contact ISUReD@ilstu.edu. 


\section{THE EFFECT OF CONCEPT MAPPING ON BACCALAUREATE NURSING STUDENTS' KNOWLEDGE ACQUISITION}

\section{PAMELA S. LASKOWSKI}

\section{Pages}

This dissertation is a series of three papers on the effect of concept mapping on baccalaureate nursing students' knowledge acquisition. The first paper is an integrative review of the literature on the use of concept mapping in nursing education. The review indicates that concept mapping has been effective in nursing education for increasing students' critical thinking. However, it shows that no studies addressing the level of nursing knowledge gained using concept mapping were identified, indicating a need for research in the area of the use of concept mapping for nursing knowledge acquisition. The second paper is a feasibility study of the methodological approaches proposed for a research study on the effect of concept mapping on nursing knowledge acquisition of nursing students. It affirms that the proposed methods of teaching concept mapping and scoring concept maps using the Concept Map Structural Scoring Method are feasible and appropriate for such a research study. The third paper is a report of the research study undertaken on the effect of concept mapping on baccalaureate nursing students' knowledge acquisition. This study reveals that utilizing concept mapping along with lecture appears to help improve baccalaureate students' nursing knowledge acquisition, although further research is needed.

KEYWORDS: nursing education; concept mapping; nursing students; knowledge acquisition 
THE EFFECT OF CONCEPT MAPPING ON BACCALAUREATE NURSING STUDENTS'

KNOWLEDGE ACQUISITION

PAMELA S. LASKOWSKI

A Dissertation Submitted in Partial

Fulfillment of the Requirements for the Degree of

DOCTOR OF PHILOSOPHY

Mennonite College of Nursing

ILLINOIS STATE UNIVERSITY

2018 
(C) 2018 Pamela S. Laskowski 
THE EFFECT OF CONCEPT MAPPING ON BACCALAUREATE NURSING STUDENTS'

KNOWLEDGE ACQUISITION

PAMELA S. LASKOWSKI

COMMITTEE MEMBERS:

Sheryl Jenkins, Chair

Kim Astroth

Cindy Kerber

Wendy Woith 


\section{ACKNOWLEDGMENTS}

I would like to thank God, first and foremost, for placing the right people in my life and giving me the courage and wisdom to fulfill this degree. Secondly, I wish to thank my committee members, Kim Astroth, Cindy Kerber, and Wendy Woith for their expertise, patience, and willingness to serve on my Dissertation Committee, and especially my chair, Sheryl Jenkins, whose guidance was invaluable. I also wish to thank my sister in heaven, Tina Delbridge Dilbeck, who directed me to "make sure you finish your PhD," shortly before she died. Finally, I wish to thank my wonderful husband, Bob, whose love and support made this possible.

P. S. L. 


\section{CONTENTS}

Page

ACKNOWLEDGMENTS

CONTENTS

TABLES

CHAPTER I: INTEGRATIVE REVIEW 1

Concept Mapping in Nursing Education: An Integrative Literature Review 1

Abstract 1

Literature Review 2

$\begin{array}{ll}\text { Critical Thinking } & 3\end{array}$

Clinical Uses 4

Studying and Learning $\quad 5$

Methodological and Measurement Issues $\quad 5$

Design Issues

$\begin{array}{ll}\text { Measurement Issues } & 7\end{array}$

$\begin{array}{ll}\text { Summary of Results } & 10\end{array}$

Conclusions \& Implications $\quad 12$

$\begin{array}{ll}\text { References } & 13\end{array}$

Appendix A: Literature Matrix 16

CHAPTER II: METHODOLOGICAL FEASIBILITY 23

Concept Map Research in Nursing Education: A Feasibility Study 23

$\begin{array}{ll}\text { Abstract } & 23\end{array}$

$\begin{array}{ll}\text { Background } & 25\end{array}$ 
$\begin{array}{ll}\text { Conceptual Framework } & 27\end{array}$

$\begin{array}{ll}\text { Methods } & 29\end{array}$

Sample \& Setting $\quad 29$

$\begin{array}{ll}\text { Procedure } & 30\end{array}$

Data Analysis $\quad 31$

$\begin{array}{ll}\text { Results } & 31\end{array}$

$\begin{array}{ll}\text { Discussion } & 32\end{array}$

Implications for Nursing Education Research 33

$\begin{array}{lr}\text { Conclusions } & 34\end{array}$

$\begin{array}{ll}\text { References } & 35\end{array}$

Appendix B: Concept Map Structural Scoring Method 40

Appendix C: Strategy for Introducing Concept Mapping 42

Appendix D: Follow-Up Questionnaire $\quad 45$

CHAPTER III: RESEARCH REPORT 46

Effect of Concept Mapping on Baccalaureate Nursing Students’ Knowledge

$\begin{array}{ll}\text { Acquisition } & 46\end{array}$

$\begin{array}{ll}\text { Abstract } & 46\end{array}$

$\begin{array}{ll}\text { Literature Review } & 47\end{array}$

$\begin{array}{ll}\text { Theoretical Framework } & 49\end{array}$

$\begin{array}{ll}\text { Method } & 52\end{array}$

Target Population \& Sampling $\quad 52$

Instruments

$\begin{array}{ll}\text { Procedure } & 54\end{array}$ 
Results

$\begin{array}{ll}\text { Discussion } & 57\end{array}$

$\begin{array}{ll}\text { Limitations } & 59\end{array}$

$\begin{array}{ll}\text { Conclusion } & 60\end{array}$

$\begin{array}{ll}\text { References } & 61\end{array}$

Appendix E: Assimilation Theory Concept Map 66

Appendix F: Strategy for Introducing Concept Mapping 67

Appendix G: Concept Mapping Structural Scoring Method 71

Appendix H: Mental Status Pretest/Posttest 72 


\section{TABLES}

Table

Page

1. Participant's Pre-instruction and Post-instruction Scores 38

2. Comparison of Scoring by Rater 1 and Rater 2

3. Group Mean Scores, Mean Differences, and Repeated Measures ANOVA 65 


\title{
CHAPTER I: INTEGRATIVE REVIEW
}

\section{CONCEPT MAPPING IN NURSING EDUCATION: AN INTEGRATIVE LITERATURE REVIEW}

\begin{abstract}
Background: Lack of nursing knowledge can be problematic for nursing students' success; concept mapping could potentially help students learn more effectively. Method: A literature review regarding concept mapping in nursing education was completed using Academic Search Premier, CINAHL, and ERIC databases from 2005 to present, and sixteen articles were included.

Results: Despite differing levels of evidence and methodological approaches used, the review of the literature provides support for concept mapping as an effective teaching method for increasing student nurses' critical thinking skills in both the clinical and classroom settings. Conclusion: Concept mapping can be used effectively for clinical preparation, care planning, to develop clinical judgment, and to evaluate critical thinking and progress throughout nursing courses. Explicit empirical evidence of whether concept mapping enhances nursing students' knowledge acquisition is missing. Further research is recommended, with attention to increased sample sizes, multi-site studies, and a focus on acquisition of nursing knowledge.
\end{abstract}

Keywords: nursing students, concept mapping, nursing education, knowledge acquisition 
Concept mapping is a graphic depiction of a concept and its propositions in a hierarchical format, with links to other concepts and examples, moving from general to specific (Novak \& Gowin, 1984). Concept mapping is especially appropriate for Generation Y learners, born from the 1980s through the 1990s, who tend to be visual and interactive learners (Ahrin \& Corimer, 2007). Although concept mapping has been supported as an effective teaching strategy for developing critical thinking (CT) in nursing education (Felver et al., 2010), there is little evidence regarding its use for acquiring nursing knowledge.

According to Assimilation Learning Theory, the acquisition of knowledge occurs through meaningful learning when concepts are subsumed into one's cognitive structure and retained for later use (Ausubel, 2000). The acquisition of nursing knowledge then, may be defined as the subsumption of nursing concepts into the cognitive structure. The effect of concept mapping on nursing knowledge acquisition needs to be studied to inform best practices in nursing education. The purpose of this review is to critically analyze the literature on concept mapping in nursing education to identify gaps in knowledge and describe methodological and measurement issues.

\section{LITERATURE REVIEW}

A review of the literature regarding concept mapping in nursing education was completed using the Academic Search Premier, Cumulative Index of Nursing and Allied Health Literature (CINAHL), and Education Resources Information Center (ERIC) databases. Search terms included nursing students and concept mapping. Only research articles on concept mapping with nursing students published during or after 2005 were included; prior to 2005, most of the literature was anecdotal in nature (Gul \& Boman, 2006). The search yielded 123 articles. Limits included: articles must be peer-reviewed, written in English, only research articles, and publication dates no earlier than 2005. After removing duplicates, reviewing abstracts, and 
imposing exclusion criteria, 16 articles remained for review. Most of the studies were focused on determining whether concept mapping develops CT in nursing students (Atay \& Karabacak, 2012; Chen, Liang, Lee, \& Liao, 2011; Decker et al., 2010; Hicks-Moore \& Pastirik, 2006; Moattari, Soleimani, Moghaddam, \& Mehbodi, 2014; Samawi, Miller, \& Haras, 2014; SinatraWilhelm, 2012; \& Tseng et al., 2011). Other identified uses of concept mapping included evaluating learning progress or academic achievement throughout a course (Hsu \& Hsieh, 2005; Jaafapour, Aazami, \& Mozafari, 2016), enhancing clinical preparedness (Gerdeman, Lux, \& Jacko 2013; Hicks-Moore \& Pastirik, 2006), assisting students to center care on nursing problems rather than medical diagnoses (Taylor \& Wros, 2007), and increasing students' selfregulation of learning and their use of deep approaches to learning (August-Brady, 2005). A variety of instruments purporting to measure CT were used in most of the studies. Some studies measured CT by concept mapping but scoring of the maps varied. No studies were found in which outcomes of the effects of concept mapping on nursing knowledge acquisition were reported. Studies on concept mapping in nursing education are presented in the Appendix A.

\section{Critical Thinking}

The development of $\mathrm{CT}$ has been a major focus in the research on concept mapping in nursing education. Eight of the 16 articles reviewed focused either entirely or partially on the

effect of concept mapping on students' CT. Several experimental or quasi-experimental studies compared CT scores before and after the use of concept mapping to scores using a traditional learning method. Students in the concept mapping groups scored higher on post-test CT scales and subscales (Atay \& Karabacak, 2012; Chen et al., 2012; Sinatra-Wilhelm, 2012; Tseng et al., 2011). One study used an instrument designed by the authors and was based on the 17 dimensions of CT in nursing (Moattari et al., 2014). Those using concept mapping increased 
cognitive skills and habits of mind necessary for CT (Moattari et al., 2014). Other researchers asserted that CT is an outcome of concept mapping (Atay \& Karabacak, 2012; Chen et al., 2011; Moattari et al., 2014; Samawi et al., 2014; Sinatra-Wilhelm, 2012). Others examined concept mapping as used for care planning (Hicks-Moore \& Pastirik, 2006), with simulation scenarios (Decker et al., 2010), and for centering nursing care around nursing, rather than medical, diagnoses (Taylor \& Wros, 2007). Finally, two studies demonstrated that concept mapping could be used throughout courses to evaluate progress and academic achievement, while using CT skills (Hsu \& Hsieh, 2005; Jaafapour et al., 2016).

\section{Clinical Uses}

Many of the studies included in this literature review described the use of concept mapping in the clinical setting (Atay \& Karabacak, 2012; Cook, Dover, Dickson, \& Colton, 2012; Gerdeman et al., 2013; Hicks-Moore \& Pastirik, 2006; Hinck et al., 2006; SinatraWilhelm, 2012; Taylor \& Wros, 2007). Atay and Karaback (2012) and Sinatra-Wilhelm (2012) found that students who used concept maps, rather than traditional columnar care plans, demonstrated higher CT scores. Concept mapping has been perceived by students to be easier, more logical, and more interesting to complete than traditional care plans (Cook et al., 2012). Hinck and colleagues (2006) found that students were satisfied with the use of concept maps for care planning and believed concept maps improved their thinking ability, prepared them for practice in the real world, enhanced their ability to understand complex situations, and improved their overall learning. Nursing students have also reported that concept mapping helped them prepare for clinical experiences (Hicks-Moore \& Pastirik, 2006) and develop clinical judgment (Gerdeman et al., 2013). 
CONCEPT MAPPING INTEGRATIVE LITERATURE REVIEW

\section{Studying and Learning}

Some studies have focused on the use of concept mapping in nursing education for classroom learning and approaches to studying and learning. The use of concept mapping in the classroom has been shown to increase learning and improve higher order and CT skills (Chen et al., 2011; Hsu \& Hsieh, 2005; Tseng et al., 2010). Concept mapping has also cultivated selfdirected learning (August-Brady, 2005), improved self-regulation of learning (Tseng et al., 2010), and fostered a deep approach to studying and learning, which is necessary for understanding meaning and retaining knowledge over time (August-Brady, 2005; Tseng et al., 2010). Two studies demonstrated an increase in concept map scores from the beginning to the end of a course, which could indicate an increase in knowledge over time (Hsu \& Hsieh, 2005; Jaafapour et al., 2016).

\section{METHODOLOGICAL AND MEASUREMENT ISSUES}

\section{Design Issues}

Multiple research designs were employed to study concept mapping in nursing education, thus providing different levels of evidence. Polit and Beck (2012) have determined levels of evidence in nursing, with the highest level (I) being systematic review or meta-analysis and the lowest level (VII) being expert opinion. The six experimental/quasi-experimental studies provide level II evidence. The rest of the studies include the following designs: mixed methods (2), case study (1), exploratory quantitative (1), qualitative pilot study (1), implementation report (2), and integrative review (1). These designs are at the lowest levels of VI or VII. Experimental design, in which participants were randomized to either the experimental or control group (Atay \& Karabacak, 2012), provides the strongest level of evidence in this review. The integrative literature review (Gul \& Boman, 2006) provides the lowest strength of evidence in the studies 
retrieved for this review. More high-level studies are needed to establish better evidence (Polit \& Beck, 2012).

Sampling is another methodological concern. All of the reviewed studies used the nonprobability sampling techniques of convenience and/or purposive sampling; additionally, most used one institution and had relatively small sample sizes. Sample sizes ranged from 1 to 120, but most had 20 to 48 participants. The use of convenience and purposive samples are subject to bias and their use means that the sample may not be representative of the population, which limits generalizability of the study (Polit \& Beck, 2012). Therefore, researchers must be cautious in their interpretation of results. Small sample sizes often do not have enough power, which also limits interpretation of results (Polit \& Beck, 2012). Unfortunately, nursing and nursing education researchers most often use convenience and/or purposive sampling because that is what they can practically access (Polit \& Beck, 2012).

Most of the experimental and quasi-experimental studies used a pre-test/post-test design; one quasi-experimental study used a post-test only design (Moattari et al., 2014). The drawback with this design is that the pre-test may affect performance on the post-test since the participants have been exposed to the outcome of interest (Polit \& Beck, 2012). The post-test only design is limited in that we do not know whether the groups were similar or comparable prior to the intervention, or whether the intervention had any effect on the outcome measure (Polit \& Beck, 2012). Feasibility and pilot studies are used to test methods for a subsequent larger, and more rigorous study; yet two of the studies in this review were pilot studies (Gerdeman et al., 2013; Hicks-Moore \& Pastirik, 2006). Feasibility and pilot studies do not answer research questions, so results of these studies must be interpreted with this in mind (Polit \& Beck, 2012). 
CONCEPT MAPPING INTEGRATIVE LITERATURE REVIEW

\section{Measurement Issues}

The use of different instruments across these studies limits the ability to compare their results in any meaningful way. The variety of instruments which have been utilized in research on concept mapping in nursing education include those that measure CT, concept map scores, and other factors related to concept mapping.

Multiple instruments have been used to measure CT. The Critical Thinking Scale (CTS), the California Critical Thinking Disposition Inventory (CCTDI), the California Critical Thinking Skills Test (CCTST), the Holistic Critical Thinking Scoring Rubric (HCTSC), and an authordeveloped instrument were all used to measure CT. The CTS was used in two of the studies in this review; it consists of 60 questions, 12 each on 5 subscales that include inference, recognition of assumptions, deduction, interpretation, and evaluation of arguments (Chen, et al., 2011). Chen and colleagues (2011) and Tseng and colleagues (2010) used the CTS to measure CT in nursing students because it is known to have content and convergent validity and high reliability with a Cronbach's alpha of .93. Atay and Karabacak (2012) translated the CCTDI, a general test of CT, into Turkish and found the instrument to have high reliability, with a Cronbach's alpha of .88 (Atay \& Karabacak, 2012). However, Hicks-Moore and Pastirik (2006) reported that the CCTDI had been used in other studies with nursing students in which the reliability fell below .80. This calls into question its ability to measure nursing students' CT abilities. Sinatra- Wilhelm (2012) used the CCTST, which has been shown to have moderate reliability with a Cronbach's alpha of .71, but she did not report a Cronbach's alpha for her study. Hicks-Moore and Pastirik (2006) used the HCTSR, which evaluates CT based on the six key competencies of interpretation, analysis, evaluation, inference, explanation, and self-regulation, using a 1 to 4 scale in which 1 is low $\mathrm{CT}$ and 4 is high $\mathrm{CT}$. The authors found the HCTSR to have adequate interrater reliability 
with an intraclass correlation coefficient of .81, and that it was useful in heightening awareness of CT competencies for both faculty and students (Hicks-Moore \& Pastirik, 2006). The final instrument was based on the 17 dimensions of CT in nursing described by Scheffer and Rubenfeld (2000), in which 7 cognitive skills and 10 habits of mind determine CT ability (Moattarri et al., 2014). No psychometric properties were reported for that instrument.

Instruments or methods for scoring concept maps were also varied. The structural scoring method was developed by the creator of concept mapping, who first used it in science education (Novak \& Gowin, 1984). This Concept Map Structural Scoring Method (CMSSM) includes a weighted scoring system determined by hierarchy (5 points each), propositions (1 point each), cross-links (10 points each), and examples (1 point each). An overall score is reported, and consecutive scores can be compared. Novak and Gowin (1984) posit that the structural scoring tool has a high level of content validity, in that it was derived from theory and includes the important theoretical variables. West, Park, Pomeroy, and Sandoval (2002) reported a moderate to high level of inter-rater reliability (pre-instruction, $r=0.65$; post-instruction, $r=0.84$ ), for the CMSSM. Hsu and Hsieh (2005) and Jaafapour and colleagues (2016) used this method, but they did not report psychometric properties from their studies. Atay and Karabacak (2012) used their own method, the Concept Map Care Plan Evaluation (CMCPE) to score participants' maps. In using CMCPE each scoring criteria item was scored as complete $=1$ point, half-complete $=1 / 2$, or incomplete $=0$, with a possible total score of 35 (Atay \& Karabacak, 2012). Atay and Karabacak (2012) reported a high reliability $(r=0.98 ; p<0.001)$ among participants, but no other psychometrics were addressed. Taylor and Wros (2012) developed a letter-grade scoring rubric to evaluate students' concept maps, but no psychometric information was reported for their study. Hinck and colleagues (2006) used an author-created scoring rubric, which provided points 
CONCEPT MAPPING INTEGRATIVE LITERATURE REVIEW

for 9 items with a possible score of 20 points. Hinck and colleagues (2006) reported moderate interrater reliability with agreement ranging from .41 to 1.0 on individual items, and a mean of .84 for all items. The rest of the studies in this literature review did not report a method for scoring the concept maps.

Nurse researchers have used other instruments to examine other factors related to concept mapping. The deep approach to learning is when information is processed for understanding and meaning, whereas the surface approach is focused on memorizing text without attention to its meaning (August-Brady, 2005). Chen and colleagues (2011) used the Approaches to Studying and Learning Inventory (ALSI), which has 36 questions on 5 subscales: deep approach, surface approach, organized studying, monitored studying, and effort management. Responses are rated on a 1 to 5 scale in which 1 is strongly disagree and 5 is strongly agree. The researchers reported Cronbach alphas ranging from 0.62 to 0.77 for moderate reliability. Chen and colleagues' (2011) study was conducted in Taiwan, where English is a second language. The ALSI was developed in English and was not clear whether the tool had been validated in nursing students with English as a second language. August-Brady (2005) used the revised Study Process Questionnaire-2 Factor (rSPQ-2F), a 20-item self-report of 10 items each for deep approach (DA) and surface approach (SA). It is rated on a 1 to 5 scale in which 1 is "never or only rarely true for me" and 5 is "always or almost always true for me" (August-Brady, 2005). The researcher reported adequate internal consistency with Cronbach's alphas of 0.82 (DA) and 0.70 (SA) in the study (August-Brady, 2005).

Two instruments were used to measure self-regulation of learning. Tseng and colleagues (2010) used the Self-Directed Learning Scale (SDLS), which measures 10 items of competency for self-directed learning. The SDLS uses a 1 (low) to 6 (high) point scale with higher scores 
indicating higher competency; the SDLS was double translated to Taiwanese and content validity was established with high reliability noted with Cronbach alphas from .90 to .92 (Tseng et al., 2010). August-Brady (2005) used the Strategic Flexibility Questionnaire (SFQ) to measure selfregulation of learning. The SFQ is a self-report on 7 items for each of 3 subscales, adaptive, inflexible, and irresolute, using the same 1 to 5 rating scale as the rSPQ-2F, and has Cronbach alphas of 0.78 to 0.81 (August-Brady, 2005).

\section{SUMMARY OF RESULTS}

The state of the science on the use of concept mapping in nursing education is clear: studies vary in design and instrumentation. Much of the research on concept mapping has explored CT skills and much has focused on the clinical setting. Most of the studies which support the use of concept mapping in nursing education for the development of $\mathrm{CT}$ have used appropriate designs and instrumentation. However, their limitations, such as small sample sizes, single sites, and lack of power analyses, prevent generalization of the results. Multiple instruments for measuring CT have been used and not enough high-level studies have been done, which complicates comparison of the studies for meta-analysis.

Research on the use of concept mapping in nursing education need not be focused solely on CT and clinical experiences; concept maps can and have been used to explore a variety of factors. Researchers have examined the use of concept mapping in classroom settings and in conjunction with other active learning strategies, such as Problem-Based Learning and simulation. Furthermore, researchers have examined the usefulness of concept mapping in evaluating learning progress, the use of clinical care concept maps in lieu of traditional care plans, the centering of care on nursing problems, as a means to increase students' deep approach to learning, and in evaluating self-regulation of learning. 
Although the literature supports these uses of concept mapping in nursing education, there are gaps in the research. Studies on the utility of concept mapping in meeting desired educational outcomes of nursing knowledge acquisition were not found. Two studies were found that explored the use of concept mapping to improve academic achievement in a course (Hsu \& Hsieh, 2005; Jaafapour et al. 2016), but neither explicitly stated nursing knowledge acquisition as a variable. When establishing best practice, the outcomes of interventions must be identified in order to decide which will provide the best results. Longitudinal studies of the effects of concept mapping on retention of nursing knowledge were not found. These gaps in the literature are concerning and research to fill these gaps may help establish best practice in nursing education.

Methodological concerns, including design and sampling, also exist. The majority of studies fall within the lower levels of the evidence hierarchy, convenience sampling may be overused, and sample sizes tend to be small. Care must be taken to avoid generalization of results when the level of evidence is not high enough. The ongoing use of convenience sampling may introduce bias into the study and the lack of power analyses compounds issues with generalizability. Given these limitations, more rigorous research methods are needed.

Issues in instrumentation can also be problematic. Instruments being used in research on the use of concept mapping in nursing education are varied, making it difficult to compare them or choose one to use. For example, at least three different CT scales, the CTS, CCTDI, and CCTST, have been used to explore concept mapping; all have similar reported reliability and validity. Researchers may find it difficult to choose the instrument that best measures the desired outcome of interest. The same may be said for the multiple methods available for scoring concept maps. 


\section{CONCLUSIONS \& IMPLICATIONS}

This review of the literature supports that concept mapping is an effective teaching method for increasing student nurses' CT skills, but few studies have examined the effectiveness of concept mapping in enhancing acquisition of conceptual nursing knowledge. Although more research is necessary, the known benefits of concept mapping should encourage nurse educators to consider the use of this teaching strategy. Outcomes research is needed on the effects of using concept mapping for nursing knowledge acquisition. Researchers need to consider using a standard method of concept map measurement, such as the CMSSM, so that comparisons may be made. Researchers should also focus on employing longitudinal experimental designs using larger sample sizes and multi-site studies to enhance power and to glean the highest levels of evidence. 
CONCEPT MAPPING INTEGRATIVE LITERATURE REVIEW

\section{REFERENCES}

Ahrin, A. O., \& Corimer, E. (2007). Using deconstruction to educate Generation Y nursing students. Journal of Nursing Education, 46(12), 562-567.

Atay, S., \& Karabacak, Ü. (2012). Care plans using concept maps and their effects on the CT dispositions of nursing students. International Journal of Nursing Practice, 18(3), 233239. Doi:10.1111/j.1440-172X.2012.02034.x

August-Brady, M. M. (2005). The effect of a metacognitive intervention on approach to and selfregulation of learning in baccalaureate nursing students. Journal of Nursing Education, 44(7), 297-304.

Ausubel, D. P. (2000). The acquisition and retention of knowledge: A cognitive view. New York, NY: Springer.

Chen, S., Liang, T., Lee, M., \& Liao, I. (2011) Effects of concept map teaching on students' CT and approach to learning and studying. Journal of Nursing Education, 50(8), 466-9.

Cook, L. K., Dover, C., Dickson, M., \& Colton, D. L. (2012). From care plan to concept map: A paradigm shift. Teaching \& Learning in Nursing, 7(3), 88-92. doi:

10.1016/j.teln.2011.11.005

Decker, S., Moore, A., Thal, W., Opton, L., Caballero, S., \& Beasley, M. (2010). Synergistic integration of concept mapping and cause and effect diagramming into simulated experiences. Clinical Simulation in Nursing, 6(4), e153-e159.

Felver, L., Gaines, B., Heims, M., Lasater, K., Lausten, G., Lynch, ..., \& Tanner, C. (2010). Best practices in teaching and learning in nursing education. New York, NY: National League for Nursing. 
Gerdeman, J. L., Lux, K., \& Jacko, J. (2013). Using concept mapping to build clinical judgment skills. Nurse Education in Practice, 13(1), 11-17. doi: 10.1016/j.nepr.2012.05.009

Gul, R. B., \& Boman, J. A. (2006). Concept mapping: A strategy for teaching and evaluation in nursing education. Nurse Education in Practice, 6, 199-206.

Hicks-Moore, S., \& Pastirik, P. (2006). Evaluating CT in clinical concept maps: A pilot study. International Journal of Nursing Education Scholarship, 3(1), 1-15.

Hinck, S. M., Webb, P., Sims-Giddens, S., Helton, C., Hope, K. L., Utley, R., ... \& Yarbrough, S. (2006). Student learning with concept mapping of care plans in community-based education. Journal of Professional Nursing, 22, 23-29.

Hsu, L., \& Hsieh, S. (2005). Concept maps as an assessment tool in a nursing course. Journal of Professional Nursing, 21(3), 141-149.

Jaafarpour, M., Aazami, S., \& Mozafari, M. (2016). Does concept mapping enhance learning outcome of nursing students? Nurse Education Today, 36, 129-132. doi:

10.1016/j.nedt.2015.08.029

Moattari, M., Soleimani, S., Moghaddam, N. J., \& Mehbodi, F. (2014). Clinical concept mapping: Does it improve discipline-based CT of nursing students. Iranian Journal of Nursing and Midwifery Research, 19(1), 70-76.

Novak, J. D., \& Gowin, D. B. (1984). Learning how to learn. New York, NY: Cambridge University Press.

Polit, D. F., \& Beck, C. T. (2012). Nursing research: Generating and assessing evidence for nursing practice (9th ed.). Philadelphia, PA: Lippincott, Williams, and Wilkins. 
Samawi, Z., Miller, T., \& Haras, M. S. (2014). Using high-fidelity simulation and concept mapping to cultivate self-confidence in nursing students. Nursing Education Perspectives, 35(6), 408-409. doi:10.5480/12-1042.1

Scheffer, B. K., \& Rubenfeld, M. G. (2000). A consensus statement on critical thinking in nursing. Journal of Nursing Education, 39, 352-359.

Sinatra-Wilhelm, T. (2012). Nursing care plans versus concept maps in the enhancement of CT skills in nursing students enrolled in a baccalaureate nursing program. Creative Nursing, 18(2), 78-84.

Taylor, J., \& Wros, P. (2007). Concept mapping: A nursing model for care planning. Journal of Nursing Education, 46(5), 211-216.

Tseng, H., Chou, F., Wang, H., Ko, H., Jian, S., \& Weng, W. (2010). The effectiveness of problem-based learning and concept mapping among Taiwanese registered nursing students. Nurse Education Today, 31, e41-e46. doi: 10.1016/j.nedt.2010.11.020

West, D., Park, J., Pomeroy, J., \& Sandoval, J. (2002). Concept mapping assessment in medical education: a comparison of two scoring systems. Medical Education, 36(9), 820-826. 


\section{APPENDIX A: LITERATURE MATRIX}

Table 1A

Matrix of Studies on Concept Mapping

\begin{tabular}{|c|c|c|c|c|c|c|c|c|}
\hline $\begin{array}{l}\text { Authors/ } \\
\text { Year }\end{array}$ & $\begin{array}{l}\text { Level of } \\
\text { Evidence }\end{array}$ & Variables & Study Design & $\begin{array}{l}\text { Sample } \\
\text { Size }\end{array}$ & $\begin{array}{l}\text { Sampling } \\
\text { Method }\end{array}$ & $\begin{array}{l}\text { Data } \\
\text { Collection }\end{array}$ & $\begin{array}{l}\text { Program } \\
\text { Type }\end{array}$ & Results \\
\hline $\begin{array}{l}\text { Atay \& } \\
\text { Karabacak, } \\
2012\end{array}$ & II & $\begin{array}{l}\text { Nursing students' } \\
\text { CT dispositions } \\
\text { (DV) } \\
\text { Students' age, GPA, } \\
\text { Concept map care } \\
\text { planning, } \\
\text { Traditional } \\
\text { columnar care } \\
\text { planning (IVs) }\end{array}$ & $\begin{array}{l}\text { Experimental pre- } \\
\text { test/post-test, } \\
\text { control group }\end{array}$ & $\begin{array}{l}80 \text { Fresh. \& } \\
\text { Soph. nursing } \\
\text { students }\end{array}$ & $\begin{array}{l}\text { Convenience } \\
\text { sample, } \\
\text { divided into } \\
\text { experimental } \\
\text { and control } \\
\text { groups via } \\
\text { simple } \\
\text { random } \\
\text { sampling }\end{array}$ & $\begin{array}{l}\text { Questionnaire } \\
\text { (CCTDI \& } \\
\text { CMCPE) }\end{array}$ & Baccalaureate & $\begin{array}{l}\text { No significant } \\
\text { differences between } \\
\text { the } 2 \text { groups' pre-test } \\
\text { scores (similar in CT } \\
\text { skills); Post-test scores } \\
\text { for experimental group } \\
\text { (concept mapping) } \\
\text { were statistically } \\
\text { significantly higher } \\
\text { than control }\end{array}$ \\
\hline $\begin{array}{l}\text { August-Brady, } \\
2005\end{array}$ & II & $\begin{array}{l}\text { Approach to } \\
\text { learning; Self- } \\
\text { regulation of } \\
\text { learning (DVs) } \\
\text { Concept mapping } \\
\text { (IV) }\end{array}$ & $\begin{array}{l}\text { Quasi- } \\
\text { experimental } \\
\text { (non-equivalent } \\
\text { control group); } \\
\text { pre-test/post-test }\end{array}$ & $\begin{array}{l}80 \text { students in } \\
\text { a } \\
\text { maternal/child } \\
\text { clinical } \\
\text { course (as } \\
\text { needed per } \\
\text { power } \\
\text { analysis) } \\
\text { Control group } \\
=45 ; \\
\text { Treatment } \\
\text { group }=35\end{array}$ & $\begin{array}{l}\text { Convenience } \\
\text { sample from } 4 \\
\text { accredited } \\
\text { nursing } \\
\text { programs in } \\
\text { Pennsylvania } \\
\text { (programs } \\
\text { from } 1 \text { private } \\
\text { and } 1 \text { public } \\
\text { university for } \\
\text { each group) }\end{array}$ & $\begin{array}{l}\text { Revised Study } \\
\text { Process } \\
\text { Questionnaire- } 2 \\
\text { Factor; Strategic } \\
\text { Flexibility } \\
\text { Questionnaire; } \\
\text { researcher- } \\
\text { constructed } \\
\text { Demographic } \\
\text { questionnaire; } \\
\text { Paired } t \text { tests and } \\
\text { ANCOVAs }\end{array}$ & Baccalaureate & $\begin{array}{l}\text { In the control group, } \\
\text { the deep approach to } \\
\text { learning mean scores } \\
\text { decreased and surface } \\
\text { learning mean scores } \\
\text { increased over the } \\
\text { course of the semester, } \\
\text { while the CM groups' } \\
\text { mean scores for deep } \\
\text { learning increased } \\
\text { with no change in } \\
\text { surface learning mean } \\
\text { scores- indicating } \\
\text { deeper more } \\
\text { meaningful learning in } \\
\text { the CM group. } \\
\text { Regarding self- } \\
\text { regulation: CM groups } \\
\text { had significant } \\
\text { increase in post-test } \\
\text { adaptive control } \\
\text { beliefs. }\end{array}$ \\
\hline
\end{tabular}


Decker,

Moore, Thal,

Opton,

Caballero, \&

Beasley. 2010
Chen, Liang, 2011

Cook, Dover,

Dickson, \&

Colton, 2012

\section{Nursing students' \\ CT, Nursing \\ students' approach \\ to studying (DV)}

Students' age,

Concept mapping,

Traditional nursing

process (IVs)

.

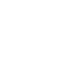

\author{
Quasi- \\ experimental, \\ 95 second- \\ semester/ $1^{\text {st }}$ \\ st/ post-test, \\ control group \\ students

$\begin{array}{ll}\text { Implemented } & 4^{\text {th }} \text { semester } \\ \text { intervention } & \text { nursing } \\ \text { following a pilot } & \text { students (no } \\ \text { study } & \begin{array}{l}\text { number } \\ \text { disclosed) }\end{array}\end{array}$ \\ disclosed)
}

Purposive

sampling

selecting 2 of

3 classes, one

for control,

one for

experimental

Faculty and

student feedback

on using concep

map care plans

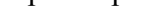

\author{
Questionnaires \\ (CTS \& ALSI) \\ RN-BSN
}

ADN

.

Faculty

evaluation and

student

satisfaction

(instruments not

described)
Purposive
sample of

nursing

students in

one US

nursing

program

\begin{tabular}{|c|c|c|c|}
\hline $\begin{array}{l}\text { Development of } \\
\text { clinical judgment, } \\
\text { Reflective thinking, } \\
\text { CT (DVs) }\end{array}$ & $\begin{array}{l}\text { Outcomes report } \\
\text { from an } \\
\text { implementation }\end{array}$ & Not specified & $\begin{array}{l}\text { Purposive } \\
\text { sample of } \\
\text { nursing } \\
\text { students in } \\
\text { one US }\end{array}$ \\
\hline $\begin{array}{l}\text { Simulation } \\
\text { debriefing, guided }\end{array}$ & & & $\begin{array}{l}\text { nursing } \\
\text { program }\end{array}$ \\
\hline
\end{tabular}

The concept mapping group had significantly higher CTS scores than those who had lecture and used only the nursing process, after controlling for pre-test scores and age

\section{Students made} significant

improvement in

development of care maps as the semester progressed and found concept maps easier, more logical, and interesting to complete than traditional care

plans. Faculty agreed to adopt the concept map format for care planning, but remained skeptical of the change while students embraced it.

Baccalaureate

Faculty found the integration of debriefing, guided reflection, reflective, journaling, and concept mapping into simulation experiences enhanced students' thoughtful practice and improved CT;

Students reported

overall satisfaction and found it helpful to

their thinking and

learning and comfort 
Gerdeman,
Lux, \& Jacko,

2013

Gul \& Boman,

2006
Clinical judgement

(DV)

Concept mapping

(IV)
Qualitative Pilot

study for

evaluative

feedback
8 junior level nursing

students in an

nursing

course
Adult Health
Integrative

Review of the

Literature of

Concept mapping

as a teaching and

evaluation

strategy for CT in

nursing education
28 articles

from 1992

2005 in performing the

simulation scenarios.

Majority of students

felt the concept

mapping with the

clinical judgment

rubric provided

guidance for

developing clinical

judgment and the

progression of clinical

judgment from

identifying problems

to using the data to

determine priorities,

interventions, and

successful outcomes

Lit Review

None

specified

Concept mapping has been identified as an effective technique for developing and

evaluating CT ability in nursing students and is a means by which to transform and

externalize CT-

helpful in taking notes,

reviewing for exams.

solving problems,

making decisions, and developing/

documenting plans of

action. Most of the

literature had been

anecdotal in nature

\section{Hicks-Moore}

VI

$\begin{array}{ll}\text { Nursing students' } & \text { Descriptive, } \\ \text { CT, Nursing } & \text { exploratory } \\ \text { students' clinical } & \text { mixed method } \\ \text { preparedness (DVs) } & \text { pilot study }\end{array}$
$182^{\text {nd }}$ year
nursing
faculty

Convenience/

Purposive

18 concept maps \& HCTSR scores,

Baccalaureate

1 student focus

group, 1 faculty

focus group -

members
Nursing students used a moderate level of CT in developing clinical concept maps. Content analysis of a focus

group of $8 / 18$ students showed they felt the 
Concept map care

planning (IV)

Hinck, Webb,

Sims-Giddens,

Helton, Hope,

Utley, ... \&

Yarbrough, S.

2006
Nursing students' learning; Student self-evaluation

Student satisfaction

(DVs)

Concept mapping (IV)
Hsu \& Hsieh, 2005
Jaafarpour, M.,

Aazami, S., \&

Mozafari, M.

2016
Quasi-

23 junior-

pre- level nursing

test/post-test

students

design

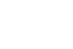

Nursing students'

learning progress

(DV)

Concept mapping

(IV)

\section{Exploratory}

toxplor

Nursing students' academic

achievement in a course (DV)

Quasi-

experimental

Case control

Cross-over

\section{3 first course \\ nursing \\ students \\ Convenience, 6 Concept maps divided into 7 teams of 6 or 7 students per team \\ per team (first \\ draft map and a \\ final map \\ discussion re: 3 \\ scenarios)}

64 second-

semester

freshman

nursing
Not explicitly stated -

appears to be

convenience
Convenience

The $1^{\text {st }}$ and last

CM scores from

the semester from

each student

(Grading criteria

developed by

authors); 21-item

Questionnaire

developed by

authors based on

Student

Assessment of

Gains Instrument

plus one open-

ended question to

say anything else

students
Concept map (CM) scores, multiple-choice quiz scores from both groups after each teaching concept maps helped them with both CT and clinical preparedness. Faculty reported that students came to

clinical prepared with a better view of the whole "big picture" of their assigned patients

Baccalaureate Significant increase of $\mathrm{CM}$ scores from $1^{\text {st }}$ to last $\mathrm{CM}(t=-3.01, p=$ $.006)$; Students rated in-class practice most favorably and reading assignments about creating CMs least

favorably, high satisfaction with grades of CMs;

Students reported CMs improved thinking ability, preparation for the real world, ability

to understand complex situations in the community, and enhanced their overall learning.

2-Year (similar to

All groups' scores improved from the third draft forward of each concept map, which supported improvement of higher order/CT.

4-year

program in

Mean scores for both cumulative exams were higher in the concept mapping groups $(p<0.001$, 
Age, Gender,

Multiple-choice

quizzes (IVs)

Moattari,

Soleimani,

Moghaddam,

\& Mehbodi,

2014

Samawi, Z.

Miller, T., \&

Haras, M. S.

2014

Nursing students'

CT (cognitive

of mind) (DV)

Age, GPA, Concept

mapping, Nursing

process (IVs)
IV

Nursing students'
self-confidence,
Satisfaction with
simulation; Nursing
students'
perceptions of
concept mapping on
their CT skills
(DVs)
High fidelity
simulation, Concept
mapping, Age,
Work hours, Prior
simulation
experience (IVs)

Concept mapping,

session for 8

weeks, 2

cumulative exam

scores at the end

of each 8-week

module; An 11-

item likert-scale

questionnaire

evaluating

perceptions of

concept mapping

Quasi-

Experimental

$324^{\text {th }}$ year

nursing

post-test only,

experimental an

control groups
Mixed methods:

exploratory

correlational and

qualitative focus

groups

48 nursing
students
enrolled in
pediatric
clinical
rotation

Convenience

Simulation

Design Scale

(SDS);

Educational

Practices

Questionnaire

(EPQ); Student

Satisfaction and

Self-Confidence

in Learning Scale

(SSSC); Focus

group discussions $p<0.02$ ); Significant

difference in mean

CM scores after

sessions $1,4, \& 8$

questionnaire showed

students perceived

$\mathrm{CMs}$ as helpful for

class, exams, and

understanding, but

time-consuming

"4-year

program" in

Iran

Chi-square showed no significant differences

in age and GPA.

Experimental (CM)

group was

significantly better in

identification,

justification and

quality of responses,

and scored

significantly better in

5 of 7 cognitive skills and 6 of 10 habits of mind.

Baccalaureate

Consistently satisfied with overall

experience; reported

high levels of self-

confidence; Age and

work hours

significantly

correlated; 3 Themes:

Students perceived

$\mathrm{CM}$ with simulation

helped to increase

advance assessment

skills, increased CT

and increased self-

confidence 
Sinatra-

Wilhelm, 2012

Nursing students'

CT skills (DV)

Concept map care

planning,

Traditional

columnar care

planning (IVs)

\begin{tabular}{|c|c|c|c|}
\hline $\begin{array}{l}\text { Mixed: } \\
\text { Experimental } \\
\text { Qualitative }\end{array}$ & $\begin{array}{l}44 \text { Soph. } \\
\text { baccalaureate } \\
\text { nursing } \\
\text { students in the } \\
\text { med-surg } \\
\text { clinical } \\
\text { rotation }\end{array}$ & $\begin{array}{l}\text { Convenience } \\
\text { sample, } \\
\text { divided into } \\
\text { experimental } \\
\text { and control } \\
\text { groups via } \\
\text { random } \\
\text { sampling }\end{array}$ & $\begin{array}{l}\text { Questionnaire } \\
\text { (CCTST); } \\
\text { Narrative report } \\
\text { of faculty }\end{array}$ \\
\hline
\end{tabular}

Case Study

centered care

planning (DV)

Organization and

thinking about data

via concept maps

(IV)

Tseng, Chou,

Wang, Ko,

Jian, \& Weng,

2010

$\begin{array}{ll}\begin{array}{l}\text { CT, Self-directed } \\ \text { learning, PBL } \\ \text { performance (DVs) }\end{array} & \begin{array}{l}\text { Quasi- } \\ \text { experimental } \\ \text { design with } \\ \text { nonequivalent }\end{array} \\ \text { Problem-based } & \begin{array}{l}\text { experimental and } \\ \text { control groups; }\end{array} \\ \text { learning (PBL), } & \text { longitudinal (pre- } \\ \text { Concept mapping } & \text { test, post-test, 6- } \\ \text { (IVs) } & \text { month follow-up } \\ & \text { test) }\end{array}$

120

baccalaureate

$\mathrm{RN}$ students

in Taiwan

nursing

student

Purposive

Concept maps

Baccalaureate

student to identify

gaps in information

and understand the

complexity of the

client situation,

teaching CT skills

Convenience CT Skills (CTS), Baccalaureate

sample from

Self-Directed

Learning Scale

one nursing

program in

(SDLS) and

Students'

Performance in

PBL Tutorial

Sessions

Questionnaire

(SPIPTSQ)
Mean differences of

CTS, SDLS and

SPIPTSQ were

significantly higher in the control group at

pre-test, but were

significantly higher in the experimental group at post-test and followup test except no

significant difference in SPIPTSQ scores at follow-up. PBL with CM cultivated 
Taiwanese nursing

students'

competencies in $\mathrm{CT}$,

self-directed learning,

group interaction,

reasoning skills and

active participation 


\title{
CHAPTER II: METHODOLOGICAL FEASIBILITY
}

\section{CONCEPT MAP RESEARCH IN NURSING EDUCATION: A FEASIBILITY STUDY}

\begin{abstract}
Background and Purpose: Little evidence on measurement of concept mapping exists. The psychometrics of Novak's Concept Map Structural Scoring Method and its teaching process are explored to be used later in a larger study. Methods: Five senior baccalaureate nursing students were taught concept mapping. They subsequently completed maps before and after instruction on the concept of delegation. The researcher and teacher scored the maps separately. A follow-up questionnaire regarding the methodological processes was completed by students. Results: Mean difference of scores was 17.6, $(t=2.60, p<.07)$. All scores increased, suggesting that the tool measures what it intends to measure. Interrater reliability was high $(r=0.99, p<$ $.01)$. Students reported methodological processes were understandable and did not recommend any changes. Conclusions: Results suggest Novak's teaching process and scoring method are acceptable to use in future studies on concept mapping in nursing education.
\end{abstract}

Keywords: concept mapping, scoring, nursing students, nursing education 
Concept mapping has been supported as an effective teaching strategy for nursing education (Felver, et al., 2010), but evidence regarding knowledge acquisition and measurement of concept maps is sparse. A concept map is a graphical representation of knowledge in which two or more interrelated concepts are linked with descriptive words to form propositions to promote meaningful learning (Novak \& Gowin, 1984). A concept map structural score is one of the few methods of measuring meaningful learning from concept mapping. The Concept Map Structural Scoring Method (CMSSM), based on Ausubelian meaningful learning, uses a weighted scoring system according to hierarchy, propositions, cross-links, and examples to obtain an overall score (Novak \& Gowin, 1984). Very little has been reported in the literature regarding the reliability and validity of the CMSSM for concept maps. Further testing of the structural scoring method is warranted.

Pilot work can be valuable in determining the feasibility and effectiveness of methods and protocols planned for a later, larger study (Conn, Algase, Rawl, Zerwic, \& Wyman, 2010). Thus, a feasibility study was conducted at a school of nursing at a small mid-western private university. The CMSSM (Novak \& Gowin, 1984) is one focus of this feasibility study (see Appendix B). The feasibility of planned methods for a future study was explored, as well as the reliability and validity of the CMSSM method of scoring concept maps for measuring knowledge acquisition. The purpose of this feasibility study was to examine (a) the methodological processes of introducing concept mapping to students, obtaining informed consent, using a preand post-instructional design and (b) reliability and validity for the CMSSM for scoring concept maps, which may be used later in in a larger study on concept mapping effectiveness regarding acquisition of nursing knowledge. 
CONCEPT MAP RESEARCH FEASIBILITY STUDY

\section{BACKGROUND}

Evidence for best practice in meeting learning outcomes in nursing education using concept mapping is limited. Studies regarding concept mapping in nursing education have mostly focused on developing critical thinking in nursing students (Atay \& Karabacak, 2012; Chen, Liang, Lee, \& Liao, 2011; Decker et al., 2010; Hicks-Moore \& Pastirik, 2006; Moattari, Soleimani, Moghaddam, \& Mehbodi, 2014; Samawi, Miller, \& Haras, 2014; Sinatra-Wilhelm, 2012; Tseng, et al., 2011). Because concept mapping shows conceptual connections that can help students solve problems, these studies have demonstrated a significant increase in post-test scores of various critical thinking scales for groups who used concept mapping instead of traditional teaching methods such as quizzes and columnar care plans (Atay \& Karabacak, 2012; Chen, Liang, Lee, \& Liao, 2011; \& Tseng, et al., 2011). Although critical thinking is necessary, the acquisition of nursing knowledge is an important learning outcome in nursing education that must occur before critical thinking can be used to solve nursing problems.

No concept mapping studies were found that addressed nursing knowledge acquisition directly. In one article, Vacek (2009) described how to use a concept mapping approach to promote critical thinking and to gain knowledge about the concept of psychosis, but no outcomes were studied. Two studies reported that the use of concept mapping had a positive effect on students' academic achievement throughout a course, but did not explicitly state if students met the learning outcomes of acquiring the conceptual knowledge expected for the course (Hsu \& Hsieh, 2005; Jaafarpour, Aazami, \& Mozafari, 2016). No outcomes research studies were found within the nursing literature. Other disciplines, such as educational psychology (McClure, Sonak, \& Suen, 1999) and medical education (West, Park, Pomeroy, \& Sandoval, 2002) have shown significant gains in students' knowledge by using concept maps. 
Concept mapping originated in science education, so most of the literature regarding scoring methods comes from the discipline of education (McClure et al., 1999; West et al., 2002). Concept maps have also been widely used to support learning in other disciplines, and literature on concept map scoring methods can be found in the fields of science, psychology, educational psychology, medicine, and teacher education (Buehl \& Fives, 2011; Harris \& Zha, 2013; McClure et al., 1999; Novak \& Gowin, 1984; West et al., 2002). There has been growth in the use of concept maps to support nursing education, but there is little extant research in the nursing literature on scoring methods and instruments to measure resulting knowledge acquisition. A valid and reliable measurement tool for scoring concept mapping is essential for establishing evidence regarding nursing knowledge acquisition using concept mapping as a teaching strategy in nursing education.

Different methods of scoring concept maps have been used in all disciplines, including the relational method and the structural method (CMSSM). The relational method focuses on whether propositions portrayed in the concept map are true and whether the relationship to other concepts is accurate, scoring points for each accurate proposition and relationship (McClure et al., 1999). According to Novak and Gowin (1984), the structural method focuses on how the map is constructed according to hierarchy, concept links, cross-links and examples and each of these is counted using a weighted scoring system to obtain a total score (see Appendix B). In the available nursing literature, only Hsu and Hsieh (2005) reported on using the CMSSM, but discussion of the method's reliability and validity was limited. One group of researchers did not score the maps at all, but instead reviewed them with the students to assess comprehension (Decker, et al., 2010); they did not describe their process for assessing comprehension. 
There is little in the literature about reliability and validity of concept map scoring methods. In a study of the relational method, known as the Protocol for Relational Scoring, gcoefficients were used to measure reliability; a g-coefficient of 0.67 to 0.76 was reported, indicating moderate reliability (McClure et al., 1999). The g-coefficient is the reliability measure derived from generalizability theory; although the measures are different it uses the same 0 to 1 scale as Cronbach's alpha in which the closer to 1, the more reliable (Webb, Shavelson, \& Haertel, 2006). In a study of the structural method, West and colleagues (2002) used inter-rater reliability as the reliability measure, showing that the CMSSM had a moderate to high level of inter-rater reliability (pre-instruction, $r=0.65$; post-instruction, $r=0.84$ ). Both scoring methods were reported as having concurrent and face validity. The psychometric properties of the CMSSM that have been reported fit adequately with intended research on concept mapping as a teaching strategy to demonstrate acquisition of basic nursing knowledge. It is the only one that has been used in nursing, and it is free to use.

\section{CONCEPTUAL FRAMEWORK}

The original purpose of the CMSSM was to measure students' learning according to Ausubel's (1963) Assimilation Learning Theory. Ausubel (2000) theorized that meaningful learning must occur for individuals to understand connections between concepts and integrate knowledge into the cognitive structure. Concepts must be linked to other concepts in a hierarchical manner from general to specific, and concepts progressively differentiate and are subsumed into the cognitive structure as new knowledge is gained (Ausubel, 1963, 2000). Three main ideas of Ausubel's $(1963,2000)$ work are the basis for scoring concept maps. These main ideas include: cognitive structure is hierarchically organized; concepts in cognitive structure undergo progressive differentiation with increased propositional linkages and recognition of 
linkages with other concepts as learning occurs; and integrative reconciliation occurs as new propositional meanings develop when two or more concepts are recognized as relatable in a new way (Ausubel, 1963).

Novak originally developed concept mapping and the structural scoring criteria for the CMSSM, based directly on Ausubelian learning theory, and established content validity of the method (Novak \& Gowin, 1984). The CMSSM is a criterion-referenced measure that can be used with any level of student in any setting. It is used to measure knowledge acquisition. The scoring of concept maps allows instructors to know how well students understand the concept being mapped. Further, scoring of consecutive concept maps following instruction allows for the instructor to evaluate learners' connections of concepts and the depth of meaningful knowledge development that may be occurring. Increased propositional linkages in proper hierarchical levels with linkages between relatable concepts is in line with integration into new knowledge as described by Ausubel (1963). This use is congruent with the intent of this study.

The CMSSM includes a weighted scoring system according to hierarchy (5 points each), propositions (1 point each), cross-links (10 points each), and examples (1 point each). An overall score is reported and consecutive scores can be compared to establish gains in knowledge. Novak and Gowin (1984) posited that the structural scoring method has a high level of content validity in that it was derived from theory and includes the variables Ausubel deemed as important to knowledge construction. West and colleagues (2002) further demonstrated moderate (pre-instructional: $r=0.65$ ) to strong (post-instructional: $r=0.84$ ) inter-rater reliability. These researchers also determined structural scores of concept maps to have predictive validity (Wilcoxon sign rank test, $p=0.004$ ) of expected change and differences in knowledge frameworks after instruction (West et al., 2002). In other words, it can measure knowledge 
CONCEPT MAP RESEARCH FEASIBILITY STUDY

acquisition. This sparse evidence of reliability and validity of the structural scoring method appears promising, but needs further research to determine its ability to measure knowledge acquisition reliably. A review of the nursing education literature revealed no studies of the reliability and validity of the CMSSM. The central questions for this study are: Does the structural scoring method of evaluating concept maps indicate some initial valid and reliable measurements for use in nursing education; and will proposed methods for a future, larger study on whether concept mapping enhances nursing knowledge acquisition be effective?

\section{METHODS}

This study used a pre-test post-test design to explore the feasibility of using the CMSSM. A follow-up survey was used to explore whether the methodological processes for obtaining consent, teaching concept mapping, and the concept mapping activity were effective.

\section{Sample \& Setting}

The convenience sample included five baccalaureate senior-level nursing students at a Midwestern private liberal arts university, who were purposefully sampled as participants in this feasibility study. The rationale for using senior level students is that they would graduate before the larger study on concept mapping would be undertaken, thereby removing any carry-over effects in the larger study from exposure to the concept mapping teaching learning strategy employed. Concept mapping had not been used before at this school. The purposeful selection of these five students occurred as it was $25 \%$ of the potential participants accessible for sampling and represented the five different levels of performance in the accessible group's coursework. Each student was representative of current course grades from A- to $\mathrm{C}+$. The participants were not current students of the researcher, nor did the researcher have any input into their grades in 
the course. No monetary or other tangible compensation was provided to the participants. Approval from the study site's Institutional Review Board was obtained prior to this study.

\section{Procedure}

Potential participants were informed of this study via personal communication and were invited to participate in the study. Informed consent was obtained from each participant. The researcher and the participants' clinical course instructor agreed to use the concept of delegation for the concept mapping activity, the participants had not yet received instruction on this topic. This activity was done outside of class and did not count toward the students' course grade. First, the participants participated in an instructional session on concept mapping as described by Novak and Gowin (1984), and taught by the researcher using the Strategy for Introducing Concept Mapping (Appendix C). After taking part in the introduction of concept mapping, participants created a concept map of delegation and students were each provided with an identifying number by the researcher. The maps were scored separately by the researcher and course instructor using the CMSSM which were the pre-instruction scores. The researcher then instructed the students on the concept of delegation; instruction was based on course instructor input and course outcomes. Participants then created a post-instruction concept map. These maps were scored separately by both the researcher and course instructor using the CMSSM, which provided the post-instruction scores. Participants completed a brief follow-up questionnaire (Appendix D) regarding clarity and understandability of the study processes for consent, introduction to concept mapping, and the concept mapping activity. A summary of the study's findings was presented to the participants when the study was completed. 


\section{Data Analysis}

The researcher and instructor followed the scoring instructions on a sample concept map individually and then together, to assess inter-rater reliability for the scoring process prior to scoring participants' concept maps. This was the method of reliability used in previous research on the CMSSM by West and colleagues (2002). The participants' pre- and post-instruction scores were entered into SPSS Version 19 for analysis with a paired $t$-test to determine any significant differences. Although statistical analysis of small sample sizes is typically considered problematic, in a frequentist statistical perspective a paired $t$ test can be used in sample sizes as small as 2 if effect size is expected to be large (deWinter, 2013). Having the researcher and course instructor each score the participants' maps allowed for determination of inter-rater reliability, determined by Pearson's $r$. Information obtained from the follow-up questionnaire was used to either validate or make appropriate changes to the study processes for the future larger study.

\section{RESULTS}

The first set of data (Table 1) includes pre- and post- instruction scores of the participants' concept maps. Pre-instruction scores ranged from 20 to 56 and post-instruction scores ranged from 34 to 79 , with mean differences ranging from +4 to +49 . The mean score for pre-instruction maps was 38.4 , the mean for post-instruction maps was 56 , showing a mean difference of 17.6. Although the scores improved, the mean difference was not significant $(t=$ $2.60, \mathrm{p}<.07)$. The second set of data (Table 2 ) included scores for each map completed by the researcher and by the course instructor for comparison of inter-rater reliability. The scores for each map by rater 1 and rater 2 were also entered into SPSS Version 19 for analysis of 
correlation with Pearson's $r$. The results showed that the raters' scoring was highly correlated ( $r$ $=0.99, p<.01)$. This demonstrates a very high inter-rater reliability.

The final data set was the aggregation of responses to the Follow-up Questionnaire (see Appendix D). All five of the participants believed the consent process to be understandable. They said they understood what would be expected of them in taking part in the larger study, and they believed the introduction to concept mapping session was sufficient for understanding how to create concept maps. Finally, none of the participants offered any recommendations for modification of the process.

\section{DISCUSSION}

Each participant did have a gain in score from pre-instruction to post-instruction, which is expected with learning. This is similar to the increases in students' scores found by West and colleagues (2002) and by Hsu \& Hsieh (2005). According to Novak \& Gowin (1984), gains in consecutive concept map scores demonstrate acquisition of knowledge. Although statistical significance was not reached, potentially due to the small sample size, the CMSSM shows promise for initial validity, as each participant's scores increased from pre-instruction to postinstruction. Since gains in scores occurred, demonstrating acquisition of knowledge, this shows that the CMSSM does measure what it is intended to measure.

The CMSSM has previously shown moderate $(r=0.65)$ to high $(r=0.84)$ inter-rater reliability (West, et al., 2002). Although the small sample size diminishes the level of meaning that can be attributed to the results, this feasibility study showed an even higher inter-rater reliability $(r=0.99)$ than that found by West et al. (2002). Reliability is a property of the instrument when used with certain people under certain conditions (Polit \& Beck, 2012). Since the CMSSM was used with students in the condition of learning a new concept for which it was 
designed, it may have enhanced the reliability. Another factor that could potentially affect interrater reliability could be the complexity of the maps, in which the more complex the maps, the more likelihood for differences in ratings. However, reliability can be improved by clearly explaining the underlying construct for the rating scale and through observer training (Polit \& Beck, 2012). Considering the high inter-rater reliability, it may be likely that the researcher's instruction for the course instructor on how to use the CMSSM was effective. It may also be that use of the CMSSM is straightforward and easy to follow.

The concept map scores varied greatly among the participants. Factors that may have affected the scores may include such things as academic achievement, GPA, level of interest in the topic, ability to learn quickly, understanding of the concept mapping process, or other unknown factors. No target "passing" level of performance had been set for the concept maps for this feasibility study. The small sample size from one site limits generalizability. These factors may need to be addressed in future studies on the effectiveness of concept mapping.

\section{Implications for Nursing Education Research}

Although the small sample size of this feasibility study may limit the meaning of the data analysis, the increases in scores are similar to what was found by others (West et al., 2002; Hsu \& Hsieh, 2005), who reported that the CMSSM was valid and reliable. The course instructor commented that the scoring tool was straight-forward and easy to use. Since participants did not think changes were necessary, no changes to the CMSSM or Strategy for Introducing Concept Mapping were recommended; and so, this scoring method and process may be used in a future study. The difference in pre-instruction and post-instruction concept map scores should be compared with another measure of knowledge, such as a test or an instructor-created expert map, to help determine adequate knowledge acquisition. Analysis of the CMSSM's performance 
should be completed each time this method is used. This will be of benefit for informing future larger studies regarding evaluation of nursing knowledge acquisition using concept mapping.

\section{CONCLUSIONS}

The CMSSM has been shown in previous studies to be a valid method for measuring knowledge acquisition from concept mapping; it also showed gains in knowledge in this feasibility study. It appears to be adequate for use in future studies, and psychometric properties must be analyzed each time it is used to build the evidence for use. The methodological procedures used in this feasibility study for introducing concept mapping were supported by the students. This also corroborates Novak and Gowin's (1984) statement that concept mapping can be used with any level of students. Further research on validity and reliability of the CMSSM is needed so that studies on nursing knowledge acquisition using concept maps will have a valid and reliable measurement method. After continued use and testing of psychometric properties of CMSSM, it could become a valuable tool for use in nursing education research regarding concept mapping. 


\section{REFERENCES}

Atay, S., \& Karabacak, Ü. (2012). Care plans using concept maps and their effects on the critical thinking dispositions of nursing students. International Journal of Nursing Practice, 18(3), 233-239. Doi:10.1111/j.1440-172X.2012.02034.x

Ausubel, D. P. (1963). The psychology of meaningful verbal learning. New York, NY: Grune and Stratton.

Ausubel, D. P. (2000). The acquisition and retention of knowledge: A cognitive view. New York, NY: Springer.

Buehl, M. M., \& Fives, H. (2011). Best practices in educational psychology: Using evolving concept maps as instructional and assessment tools. Teaching Educational Psychology, $7(1), 62-87$.

Chen, S., Liang, T., Lee, M., \& Liao, I. (2011) Effects of concept map teaching on students' critical thinking and approach to learning and studying. Journal of Nursing Education, $50(8), 466-9$.

Conn, V. S., Algase, D. L., Rawl, S. M., Zerwic, J. J., \& Wyman, J. F. (2010). Publishing pilot intervention work. Western Journal of Nursing Research, 32(8), 994-1010. doi: $10.1177 / 0193945910367229$

Decker, S., Moore, A., Thal, W., Opton, L., Caballero, S., \& Beasley, M. (2010). Synergistic integration of concept mapping and cause and effect diagramming into simulated experiences. Clinical Simulation in Nursing, 6(4), e153-e159.

deWinter, J. C. F. (2013). Using the Student's $t$-test with extremely small sample sizes. Practical Assessment, Research \& Evaluation, 18(10). Available online: http://pareonline.net/getvn.asp?v=18\&n=10 
Felver, L., Gaines, B., Heims, M., Lasater, K., Lausten, G., Lynch, ..., \& Tanner, C. (2010). Best practices in teaching and learning in nursing education. New York, NY: National League for Nursing.

Harris, C. M. \& Zha, S. (2013). Concept mapping: A critical thinking technique. Education, 134(2), 207211.

Hsu, L., \& Hsieh, S. (2005). Concept maps as an assessment tool in a nursing course. Journal of Professional Nursing, 21(3), 141-149.

Jaafarpour, M., Aazami, S., \& Mozafari, M. (2016). Does concept mapping enhance learning outcome of nursing students? Nurse Education Today, 36, 129-132. doi:10.1016/j.nedt.2015.08.029

McClure, J. R., Sonak, B., \& Suen, H. K. (1999). Concept map assessment of classroom learning: Reliability, validity, and logical practicality. Journal of Research in Science Teaching, 36(4), 475-492.

Moattari, M., Soleimani, S., Moghaddam, N. J. \& Mehbodi, F. (2014). Clinical concept mapping: Does it improve discipline-based critical thinking of nursing students. Iranian Journal of Nursing and Midwifery Research, 19(1), 70-76.

Novak, J. D., \& Gowin, D. B. (1984). Learning how to learn. New York, NY: Cambridge University Press.

Samawi, Z., Miller, T., \& Haras, M. S. (2014). Using high-fidelity simulation and concept mapping to cultivate self-confidence in nursing students. Nursing Education Perspectives, 35(6), 408-409. doi:10.5480/12-1042.1

Sinatra-Wilhelm, T. (2012). Nursing care plans versus concept maps in the enhancement of critical thinking skills in nursing students enrolled in a baccalaureate nursing program. Creative Nursing, 18(2), 78-84. 
Tseng, H., Chou, F., Wang, H., Ko, H., Jian, S., \& Weng, W. (2011). The effectiveness of problem-based learning and concept mapping among Taiwanese registered nursing students. Nurse Education Today, 31, e41-e46. doi: 10.1016/j.nedt.2010.11.020

Vacek, J. E. (2009). Using a conceptual approach with a concept map of psychosis as an exemplar to promote critical thinking. Journal of Nursing Education, 48(1), 49-53.

Webb, N. M., Shavelson, R. J., \& Haertel, E. H. (2006). Reliability coefficients and generalizability theory. Handbook of Statistics, 26, 1-44. doi: 10.1016/S01697161(06)26004-8

West, D., Park, J., Pomeroy, J., \& Sandoval, J. (2002). Concept mapping assessment in medical education: a comparison of two scoring systems. Medical Education, 36(9), 820-826. 
Table 1

Participant's Pre-instruction and Post-instruction Scores

\begin{tabular}{cccc}
\hline Participant & Pre-instruction & Post-instruction & Difference \\
\hline 01 & 30 & 79 & +49 \\
02 & 55 & 70 & +15 \\
03 & 31 & 35 & +4 \\
04 & 56 & 62 & +6 \\
05 & 20 & 34 & +14 \\
Mean Difference & & & $17.6^{*}$ \\
\hline
\end{tabular}

Note: *paired $t$-test: $t=2.60, p<.07$ 
Table 2

Comparison of Scoring by Rater 1 and Rater 2

\begin{tabular}{|c|c|c|c|c|}
\hline & Participant & Rater 1 & Rater 2 & Difference \\
\hline \multicolumn{5}{|l|}{ Pretest } \\
\hline & 01 & 30 & 30 & 0 \\
\hline & 02 & 55 & 55 & 0 \\
\hline & 03 & 31 & 31 & 0 \\
\hline & 04 & 56 & 56 & 0 \\
\hline & 05 & 20 & 20 & 0 \\
\hline \multicolumn{5}{|l|}{ Postest } \\
\hline & 01 & 79 & 79 & 0 \\
\hline & 02 & 70 & 74 & 4 \\
\hline & 03 & 35 & 35 & 0 \\
\hline & 04 & 62 & 62 & 0 \\
\hline & 05 & 34 & 34 & 0 \\
\hline
\end{tabular}

Note: Pearson's $r=0.99, p<.01$ 


\section{APPENDIX B: CONCEPT MAP STRUCTUAL SCORING METHOD}

\section{Scoring Criteria}

1. Concept-link:

Is the meaning relationship between two concepts indicated by a connecting line/arrow and linking word(s)? Is the relationship valid? If yes, score 1 point for each valid concept-link.

2. Hierarchy:

Does the map show hierarchy? Is each subordinate concept more specific and less general than the concept shown above it (in the context of the material being mapped)? If yes, score 5 points for each valid level of hierarchy.

3. Cross-links:

Does the map show meaningful connections between one segment of the concept hierarchy and another segment? Is the relationship shown significant and valid? If yes, score 10 points for each cross-link that is both significant and valid.

4. Examples:

Score 1 point each for specific events or objects that are valid instances of those designated by the concept label.

\section{Invalid Components:}

Inclusion of invalid components in the concept map receive zero (0) points.

\section{Scores}

Concept-links: $\quad$ Number of valid concept-links _ $\quad \mathrm{x} 1=$

Hierarchy: Number of valid hierarchy levels __ $\quad$ x $5=$

Cross-links: Number of valid \& significant cross links __ x 10= 
Examples:

Structural Score:
Number of valid examples __ $\mathrm{x} 1=$

(Total points)

Note: Blanket permission granted by authors in Novak, J. D., \& Gowin, D. B. (1984). Learning how to learn. New York, NY: Cambridge University Press. 


\section{APPENDIX C: STRATEGY FOR INTRODUCING CONCEPT MAPPING}

A. Activities to prepare for concept mapping

1. Make two lists of words on the blackboard or overhead projector using a list of familiar words for objects and another list for events. For example, object words might be car, dog, chair, tree, cloud, book; and event words could be raining, playing, washing, thinking, thunder, birthday party. Ask the students if they can describe how the two lists differ. Try to help them recognize that the first list is things or objects and the second list is happenings or events, and label the two lists

2. Ask the students to describe what they think of when they hear the word car, dog, etc. Help them recognize that even though we use the same words, each of us may think of something a little different. These mental images we have for words are our concepts; introduce the word concept.

3. Repeat the activities in step 2, using event words. Again, point out the differences in our mental images, or concepts, of events. You may want to suggest at this point that one reason we have trouble understanding each other sometimes is that our concepts are never quite identical even though we know the same words. Words are labels for concepts, but each of us must acquire our own meanings for words.

4. Now list words such as are, where, the, is, then, with. Ask students what comes to their minds when they hear each of these words. These are not concept words; we call them linking words and we use them in speaking and writing. Linking words are used together with concept words to construct sentences that have meaning.

5. Proper nouns are not concept words but rather names of specific people, events, places, or objects. Use some examples and help students to see the distinction between labels for regularities in events or objects and those for specific events or objects (proper nouns).

6. Using two concept words and linking word(s), construct a few short sentences on the board to illustrate how concept words plus linking words are used by humans to convey meanings. Examples would be: The dog is running. Or, There are clouds and thunder.

7. Have students construct a few short sentences of their own, identify the concept words and tell whether each is an object or an event, and also identify the linking words.

8. If you have bilingual students in the class, have them present some foreign words that label the same events or objects. Help the children recognize that language does not make the concept, but only serves as the label we use for the concept.

9. Introduce some short but unfamiliar words to the class such as dire, terse, or canis. These are words that stand for concepts they already know, but have somewhat special meaning. Help students see that meanings of concepts are not rigid and fixed, but can grow and change as we learn more. 
10. Choose a section of a textbook (one page is sufficient) and duplicate copies for the children. Choose a passage that conveys a definite message. As a class, ask them to read the passage and identify key concepts. (Usually 10 to 20 relevant concepts can be found in a single page of text material) Also have the students note some linking words and concept words that are less important to the story line.

\section{B. Concept mapping activities}

1. Select a particularly meaningful paragraph or two from a text and select the key concepts, that is, those concepts necessary for understanding the meaning of the text. List these concepts on the board (or overhead projector) as they are identified. Now discuss with the students which concept is most important, most inclusive idea in the text.

2. Put the most inclusive concept at the head of a new list of rank-ordered concepts. List the next most-general, most inclusive concepts, working through the first list until all concepts are rank ordered. There will not always be agreement among the students on the ordering, but usually only a few major differences in ranking of concepts will arise. This is OK because it suggests that there may be more than one way to see the meaning of the text.

3. Now begin constructing a concept map, using the rank ordered list a s a guide in building the concept hierarchy. Have students help in choosing good linking words to form propositions [concept-links] shown by lines on the map. One good way to have them practice map making is to have students write concept words and linking words on paper rectangles and then rearrange those rectangles as they get new insights on the map organization.

4. Now look for cross-links between concepts in another part of the concept "tree." Have students help to choose linking words for the cross-links.

5. Most first effort maps have poor symmetry or some concept clusters poorly located relative to other more closely related concepts or clusters of concepts. Reconstruct the map if this would be helpful. Point out to students that at least one and sometimes two or three reconstructions of a map are needed to show a good representation of propositional meanings as they understand them.

6. Discuss the concept map scoring criteria and score the concept map constructed. Point out possible structural changes that might improve the meaning, and perhaps the score, of the map

7. Have the students select a section of text or other material and repeat steps 1-6 on their own (or in groups of two or three).

8. Student-constructed maps can be presented to the class on the blackboard or overhead projector. "Reading" the map should make clear to other students in the class what the text was about, as interpreted by the map maker. 
9. Have students construct a concept map for ideas important in a hobby, sport, or special interest they have. These might be posted around the room and informal discussion encouraged.

10. Incorporate one or two concept mapping questions in your next test to illustrate that concept mapping is a valid evaluation procedure that demands hard thinking and can illustrate understanding of the subject matter.

Note: Adapted from 'Strategies for introducing concept mapping in grades seven through college', in Novak, J. D., \& Gowin, D. B. (1984). Learning how to learn. New York, NY: Cambridge University Press, p.p. 32-34. (Blanket permission granted by authors in text.) 


\section{APPENDIX D: FOLLOW-UP QUESTIONNAIRE}

1. Was the consent process efficient and understandable?

2. Did you understand what would be expected of you in taking part in this study?

3. Was the introduction to concept mapping session sufficient for what was expected of you?

4. If you answered "No" to any of the above, what could be changed or modified to improve these processes? 


\title{
CHAPTER III: RESEARCH REPORT
}

\section{EFFECT OF CONCEPT MAPPING ON BACCALAUREATE NURSING STUDENTS' KNOWLEDGE ACQUISITION}

\begin{abstract}
Background: Researchers have found that concept mapping is an effective teaching method for enhancing student nurses' critical thinking skills, clinical care, and judgment. However, evidence regarding whether concept mapping enhances students' nursing knowledge acquisition is lacking. Method: An experimental, pre-test post-test design was used, with a sample of 44 sophomore baccalaureate nursing students. Each student was enrolled in a lab group and lab groups were randomly assigned to the intervention or control group. The intervention group utilized concept mapping and traditional lecture to teach students about a specific concept, while the control group received the lecture alone. Results: Although statistical analysis did not show a significant difference in using concept mapping with lecture compared to lecture alone, both concept map scores and post-test scores did increase, suggesting a gain in nursing knowledge.

Conclusions: Results support the use of concept mapping to enhance acquisition of conceptual nursing knowledge in nursing education.
\end{abstract}

Keywords: nursing students, nursing education, concept mapping, learning strategy 


\section{EFFECT OF CONCEPT MAPPING ON KNOWLEDGE ACQUISITION}

Nursing knowledge includes the basic concepts involved in the practice of nursing, including communication, comfort, crisis, safety, self-care, stress, and others. Knowledge acquisition is defined as the meaningful learning of new information relevant to previously learned concepts; the new information is subsumed into the cognitive structure where it is retained for later recall (Ausubel, 2000). Concept mapping is a graphical depiction of knowledge showing linkage of two or more interrelated concepts to promote meaningful learning (Novak \& Gowin, 1984). Concept mapping has been supported as an effective teaching/learning method for developing critical thinking in nursing students (Atay \& Karabacak, 2012; Chen, Liang, Lee, \& Liao, 2011; Felver et al., 2010 Moattari, Soleimani, Moghaddam, \& Mehbodi, 2014; Samawi, Miller, \& Haras, 2014), but evidence regarding the use of concept mapping for nursing knowledge acquisition is lacking. The purpose of this study was to determine if concept mapping improved nursing knowledge acquisition among nursing students. The aim was to provide empirical evidence while answering the research question: What is the effect of concept mapping and traditional lecture versus traditional lecture alone on the acquisition of baccalaureate nursing students' nursing knowledge?

\section{LITERATURE REVIEW}

Concept maps have been used as a learning strategy in a variety of disciplines, including the natural sciences, psychology, medicine, and teacher education. Concept mapping was first used with junior high school science students and later applied to college students (Novak \& Gowin, 1984). Recent studies have shown that concept mapping has been used effectively at the college level in a variety of disciplines to improve test scores (Blunt \& Karpicke, 2014; Harris \& Zha, 2017; Veronese, Richards, Pernar, Sullivan, \& Schwartzstein, 2013), assess understanding (Burrows \& Mooring, 2015; Francis, 2015), predict course achievement (Koc, 2012), and 


\section{EFFECT OF CONCEPT MAPPING ON KNOWLEDGE ACQUISITION}

improve students' critical thinking abilities (Bixler, Brown, Way, Ledford, \& Mahan, 2015).

These studies from other disciplines have found concept mapping to be an effective strategy.

Nurse educators use concept mapping in a variety of ways (Atay \& Karabacak, 2012;

Chen et al., 2011; Gerdeman, Lux, \& Jacko 2013; Hsu \& Hsieh, 2005; Taylor \& Wros, 2007;

Tseng et al., 2011). Most nursing studies are aimed at determining whether concept mapping develops critical thinking in nursing students (Atay \& Karabacak, 2012; Chen et al., 2011;

Moattari et al., 2014; Samawi et al., 2014; Sinatra-Wilhelm, 2012; Tseng, et al., 2011). Other uses of concept mapping in nursing education included monitoring learning progress (Hsu \& Hsieh, 2005; Jaafarpour, Aazami, \& Mozafari, 2016), assessing clinical preparedness

(Gerdeman, Lux, \& Jacko 2013; Hicks-Moore \& Pastirik, 2006), assisting students to center care on nursing problems rather than medical diagnoses (Taylor \& Wros, 2007), and increasing students' deep approach to and self-regulation of learning (August-Brady, 2005; Tseng et al., 2011). Most of these studies measured critical thinking using several different instruments and the methods for scoring concept maps also varied. No studies were found explicitly addressing the effect of concept mapping on nursing knowledge acquisition.

Concept mapping has been perceived by nursing students to be easier, more logical, and more interesting to complete than traditional care plans (Cook, Dover, Dickson, \& Colton, 2012). Students have been satisfied with the use of concept maps for care planning and for use in conjunction with simulation (Decker, et al., 2010; Samawi et al., 2014). Hinck and colleagues (2006) used concept maps rather than traditional care plans with junior baccalaureate students; their students reported high satisfaction with grades received on concept maps when graded using a researcher-developed rubric. Students asserted that they improved in thinking ability, preparation for practice, ability to understand complex situations, and overall learning (Hinck et 


\section{EFFECT OF CONCEPT MAPPING ON KNOWLEDGE ACQUISITION}

al., 2006). Further, nursing students felt that concept mapping helped them with clinical preparedness (Hicks-Moore \& Pastirik, 2006) and clinical judgment (Gerdeman et al., 2013).

The use of concept mapping in the classroom has been shown to improve learning (Chen et al., 2011; Hsu \& Hsieh, 2005; Jaafarpour et al., 2016; \& Tseng et al., 2011). Two studies demonstrated an increase in concept map scores from the beginning to the end of a course; this suggested that students' knowledge increased, but the authors did not explicitly report it as such (Hsu \& Hsieh, 2005; Samawi et al., 2014). Vacek (2009) described the use of a concept mapping approach to promote critical thinking and to gain knowledge about the concept of psychosis, but it was purely descriptive and no outcomes were studied. Jaafarpour and colleagues (2016) reported that concept mapping had a positive effect on students' academic achievement, but did not definitively state what they meant by academic achievement. None of these studies measured knowledge acquisition explicitly. Further research is needed concerning the use of concept mapping in nursing education, and specific exploration of concept mapping's impact on knowledge acquisition is warranted.

\section{THEORETICAL FRAMEWORK}

Novak and Gowin (1984) describe concept mapping as a dynamic teaching and learning method to promote meaningful learning based on Ausubel's (1963) Assimilation Learning Theory (see Appendix E). Cognitive structure is one's unique configuration of knowledge in the mind of how concepts are connected, and is built by meaningful learning so that information is retained for later use (Ausubel, 1963). According to Ausubel (2000), rote memorization learning is arbitrary and does not develop cognitive structure, whereas meaningful learning is a nonarbitrary process and integrates concepts into the cognitive structure. Concepts may be objects, events, situations, or properties that possess common critical attributes and have names; these are 


\section{EFFECT OF CONCEPT MAPPING ON KNOWLEDGE ACQUISITION}

the main units of cognitive structure and necessary for comprehension and understanding (Ausubel, 2000). Knowledge is the meaningful product of the psychological interaction of concepts, or culturally meaningful ideas, with relevant background ideas (Ausubel, 2000). Potentially meaningful material is connected with prior knowledge and is subsumed under a previously learned concept; continued interaction with the material helps to differentiate it from the previous concept until it is integrated into a new place in the cognitive structure. It is then consolidated in the hierarchy of the cognitive structure where it can be retained (Ausubel, 2000). The hierarchical structure is built from general or superordinate concepts to specific or subordinate concepts, and changes as new knowledge is integrated (Ausubel, 2000). Acquisition of this knowledge can be measured by pre- and post-instruction concept map scores (Novak \& Gowin, 1984).

Concept mapping is a metacognitive approach to learning that encourages learners to process information more deeply for understanding and may promote critical thinking through meaningful learning (Novak \& Gowin, 1984). The use of concept maps is theorized to increase knowledge acquisition and fits well with assimilation learning theory (Novak \& Gowin, 1984). Meaningful learning can occur in situations of discovery and reception learning (Ausubel, 2000). According to Ausubel (1963), discovery learning occurs when the principal content is not given, but is independently discovered by the learner. An example of discovery learning is when a learner determines how to choose the correct maze pathway to reach the target. Reception learning occurs when the content of what is to be learned is directly presented to the learner, who must internalize it for later use (Ausubel, 2000). Typical nursing classrooms primarily promote learning by requiring students to listen to lectures and presentations, which would be considered reception learning according to Ausubel (2000). 


\section{EFFECT OF CONCEPT MAPPING ON KNOWLEDGE ACQUISITION}

Knowledge construction and development is dynamic and therefore compatible with the active process of concept mapping. The constructivist perspective of Ausubel's (2000) assimilation learning theory is congruent with concept mapping and evaluation of students' levels of knowledge development. Constructivism has been described as making meaning and making sense of the world through engagement with objects in the world (Crotty, 1998). A constructivist view of nursing would be that nursing students engage with objects in the nursing world, therefore they can construct meaning and make sense of nursing (Peters, 2000). Nursing concepts can be related to prior knowledge of subjects such as anatomy, physiology, psychology, etc. New knowledge can be constructed and retained as more potentially meaningful material is introduced throughout the nursing education program. For example, students are knowledgeable as to the physiology of the human heart and lungs, so they can use that knowledge to understand and retain new concepts related to heart failure and integrate the new knowledge into their cognitive structures. Meaningful learning is necessary for the acquisition and retention of conceptual nursing knowledge for future use in solving nursing problems.

Concept mapping can represent the interaction of students' prior knowledge and new material for meaningful learning and may help them acquire and retain nursing knowledge. The Ausubelian (2000) principle of integrating conceptual knowledge into the cognitive structure for retention frames the rationale for use of concept mapping in the acquisition of nursing knowledge, and supports the purpose of this study. The structural scoring method used in this study is derived directly from and based on Ausubel's theory (Novak \& Gowin, 1984). In this study, it was used to determine whether students acquired the necessary conceptual nursing knowledge. Meaningful learning and integration of knowledge into the cognitive structure (Ausbel, 2000) corresponds to nursing students' assimilation of nursing conceptual knowledge 


\section{EFFECT OF CONCEPT MAPPING ON KNOWLEDGE ACQUISITION}

for later use. Ausubel's (2000) theory is used to explain how nursing students acquire conceptual nursing knowledge, since nursing students must be able to integrate nursing concepts into their cognitive structures to later recall for passing NCLEX-RN and eventually making nursing decisions.

\section{METHOD}

The researcher conducted a quantitative study to best answer the research question and meet the aim of providing empirical evidence as to whether concept mapping enhances nursing knowledge acquisition. The pre-test post-test experimental design allowed for the comparison of groups before and after the intervention and the assessment of both group differences and change within groups (Polit \& Beck, 2012). The main variable of interest was nursing knowledge acquisition, which was defined by the researcher as integration of nursing concepts into the cognitive structure. The two ways nursing knowledge acquisition was measured included increased scores from pretest to posttest on a 15-item quiz and increased scores from preinstruction to post-instruction concept maps.

\section{Target Population \& Sampling}

The target population was a convenience sample of sophomore, baccalaureate nursing students enrolled in a health assessment course at a public university in the Midwestern United States. Inclusion criteria were: aged 18 years or older; current enrollment in the health assessment nursing course; ability to read, write, and understand English. Exclusion criteria were: the inability to meet the identified inclusion criteria. A power analysis using G Power for repeated measures ANOVA was completed to determine that the necessary total sample size was 34 , or 17 in each group, to achieve a moderate effect size at $\alpha$ of .05 and $80 \%$ power. 


\section{EFFECT OF CONCEPT MAPPING ON KNOWLEDGE ACQUISITION}

\section{Instruments}

Novak and Gowin's (1984) Concept Map Structural Scoring Method (CMSSM) includes a scoring system weighted according to the structure of the concept map. The hierarchical arrangement of the map illustrates linkage of concepts; the most general concept appears at the top of the map and subordinate concepts are placed below. Concepts become more specific moving down the map. A superordinate concept linked to a subordinate concept represents one level of hierarchy. Learners are awarded 5 points for each level of hierarchy. Propositions refer to two linked concepts; learners are awarded 1 point for each valid concept-link. Cross-links refer to connections between one segment of the concept hierarchy and another segment in a different hierarchical branch. Learners receive 10 points for each valid cross-link. Examples refer to specific, valid examples of the concept. Learners receive 1 point for each example. An overall score is reported and consecutive scores can be compared (see Appendix G). Score ranges are variable depending on the depth of the concept being mapped.

Novak and Gowin (1984) posited that the structural scoring tool has a high level of content validity in that it was derived from theory and includes the important theoretical variables of hierarchy, interactions of concepts, and integration into the cognitive structure. McClure, Sonak, and Suen (1999) demonstrated concurrent validity with statistically significant correlations with a similarity measure. West, Park, Pomeroy, and Sandoval (2002) reported a moderate level of inter-rater reliability (pre-instruction, $r=0.65$; post-instruction, $r=0.84$ ). Knowledge frameworks are expected to change after instruction and structural scores of concept maps are a valid measure of increases in post-instruction knowledge (West, Park, Pomeroy, \& Sandoval, 2002). The CMSSM stems from this study's theoretical framework and it has been used previously with nursing students (Hsu \& Hsieh, 2005). 


\section{EFFECT OF CONCEPT MAPPING ON KNOWLEDGE ACQUISITION}

A 15-item multiple-choice test on the topic of mental status was developed by the researcher and served as both the pre- and post-test of nursing knowledge of mental status (see Appendix H). It was determined to have face validity by two experts in mental health nursing and the instructor of the health assessment course. The instructor verified that all content in the 51-item test would be covered in the lecture. The percent correct was used as the score. The following is an example of pre- post-test items:

Mental status is best defined as:
A. The temporary expression of feeling or state of mind
B. Prolonged display of feelings that color the emotional life
C. The awareness of the objective world in relation to self
D. A person's emotional and cognitive functioning

The following demographic data were also collected: age, gender, prior concept mapping experience (yes or no), and grade point average (GPA).

\section{Procedure}

The researchers obtained IRB approval from the study site and permission from the health assessment course instructor to use the class for recruitment of subjects for this study. The PI met with students during the first class of the semester, explained the study, and invited them to participate. Those interested read and signed the informed consent form. All students were asked to take the 15-item pre-test on mental status, the course topic of interest, along with the attached demographic questionnaire described above. We only used data from those who had agreed to participate and destroyed data from those who did not agree to participate. The course contained 11 lab sections which were randomized into the intervention or control group by randomly drawing group names from a cup. The intervention group consisted of 6 lab groups, 


\section{EFFECT OF CONCEPT MAPPING ON KNOWLEDGE ACQUISITION}

which received concept mapping and lecture; the remaining 5 lab groups were placed in the control group, which received lecture alone.

The PI provided a 30-minute concept mapping instructional session for all students during their first health assessment lab. These were completed prior to the traditional classroom lecture on mental status. No lab instructors or course faculty were present during concept mapping instructional sessions. During the instructional sessions, the PI adhered to Novak and Gowin's (1984) protocol for teaching concept mapping. This protocol includes a specific list of activities to prepare for concept mapping and a specific set of actual concept mapping activities to be completed in step by step fashion (see Appendix F). Due to time constraints, the protocol was completed through step 6 of concept mapping activities. No instruction on the concept of mental status was presented; only instruction on how to concept map was provided. At the conclusion of the concept mapping instructional sessions, control groups were dismissed to attend their regularly scheduled lab activities, while intervention groups were given 10 more minutes to complete a pre-instruction concept map for mental status. The intervention group was also informed that they would be asked to develop a concept map during the upcoming class lecture on mental status, instead of taking traditional notes. Further, they could review and revise their concept map in the last 10 minutes of class, before submitting it at the end of class. The preinstruction maps were scored using the CMSSM immediately after they were submitted.

The PI returned to class the following week on the day of the mental status lecture to remind those in the intervention group to develop a mental status concept map during lecture, in lieu of taking traditional notes. The PI reminded them to review and make revisions before turning in the post-instruction concept map at the end of class. After the lecture, both intervention and control groups completed the 15 -item post-test. 


\section{EFFECT OF CONCEPT MAPPING ON KNOWLEDGE ACQUISITION}

The PI scored both groups' post-tests as the percent correct and analyzed and scored the intervention group's post-instruction concept maps using the CMSSM. Pre- and post-test scores and demographic data for each group, and pre-instruction and post-instruction concept map scores for the intervention group, were entered into SPSS, version 22 (IBM Corp., 2013). Demographic data were analyzed with descriptive statistics and $t$ tests to compare groups. Mean test scores were calculated and compared between the two groups using repeated measures ANOVA, with an alpha level of 0.05 to indicate significance.

\section{RESULTS}

Originally, 53 students out of 63 available agreed to participate, but 9 (4 from control group, 5 from experimental group) provided incomplete data and were removed from analysis, leaving $n=44$ (22 in each group) for analysis. Ages of participants ranged from 19 to 21 years with a mean age of 19.5; age did not significantly differ between those in the intervention and control groups. Thirty-seven (84\%) participants were female and 7 (16\%) were male; gender did not significantly differ between groups. Only 4 students (9\%) had any prior experience with concept mapping, but there was no significant difference in test scores between those who had prior experience and those who did not. The intervention group had a slightly lower GPA (3.62) than the control group (3.68), but the difference was not significant $(t=.616, p=.541)$. Overall, these results suggest the intervention and control groups were similar at the beginning of the study.

The reliability of the 15-item test was determined using the Kuder-Richardson Formula $20[\mathrm{KR}(20)]$. The interpretation of the $\mathrm{KR}(20)$ depends on the test's purpose; if the purpose is to ensure that all students have mastered essential concepts, such as in this study, we are to look for a $\mathrm{KR}(20)$ close to 0.00 , where -0.1 to 0.1 demonstrates high reliability (Educational 


\section{EFFECT OF CONCEPT MAPPING ON KNOWLEDGE ACQUISITION}

Assessments Corporation, 2018). The KR(20) in this study was -0.14 , showing moderately high reliability for the test's purpose of testing mastery of the concept of mental status by all students. Having increased the number of items on the test may have increased reliability, but time allotted for testing was limited due to it being given during a class period.

The intervention group scored slightly higher on the post-test than the control group (See Table 3). The means for the intervention group's pre-test and post-test was 60.08 , and 73.85 , respectively, with a mean difference of 13.77. The means for the control group's pre-test and post-test were 59.92 and 72.85 , respectively, with a mean difference of 12.93 . Although the intervention group had higher post-test scores, the difference was not statistically significant $(p=$ .778). There was a significant increase in scores on the 15 -item test from pre- to post test for both intervention $(F[1,21]=70.816, p<.001)$ and control groups $(F[1,21]=90.14, p<.001)$. This suggests that knowledge was acquired by both groups.

The intervention group had a significant increase in concept map scores from pre- to post- instruction $(F[1,21]=37.624, p<.001)$. Means for the intervention group's pre- and postinstruction concept map scores were 26.14 and 52.32, respectively, with a mean difference of 26.18. This also suggests knowledge acquisition for the intervention group.

\section{DISCUSSION}

The results of this study demonstrate significant increases in nursing students' knowledge acquisition among both intervention and control groups from pre- to post-instruction. This is an expected change after instruction (Novak \& Gowin, 1984). Other studies have also found significant increases in scores from pre-test to post-test (Hsu \& Hsieh, 2005; Jaafarpour et al., 2016). 


\section{EFFECT OF CONCEPT MAPPING ON KNOWLEDGE ACQUISITION}

Some researchers have found that concept map scores significantly improved each time, and continued to improve over time (Jaafarpour et al., 2016; Tseng et al., 2011). In our study the students' concept map scores improved significantly from the first to second concept map, similar to findings by Jaafarpour and colleagues (2016) and Tseng and colleagues (2011). However, this contrasts with the findings of Hsu and Hsieh (2005), whose participants scored lower on the first and second concept map attempts, and did not improve until the third attempt. It may be that students in Hsu and Hsieh's (2005) study took longer to grasp the concept mapping process. It is also possible that inclusion of the concept mapping instructional session, using Novak and Gowin's (1984) strategy, may have contributed to earlier improvement in our study.

In a study by Tseng and colleagues (2011), students were able to receive feedback on their concept maps and clarify misunderstandings prior to submitting their consecutive concept maps. Evaluation of those who used concept maps demonstrated an improvement in critical thinking scores on the CTS (Tseng et al., 2011). Although our study did not address critical thinking, knowledge gains were apparent in the improved concept map and posttest scores in the intervention group. Our participants experienced this improvement without receiving feedback on first drafts. Variations in teaching styles of the instructors may have contributed to this difference.

In a study conducted in an Iranian nursing school, Jaafarpour and colleagues (2016) used their actual course exams rather than the topical test utilized in our study. Regardless, both studies showed higher scores on the posttests by those who used concept mapping as opposed to those in the control group who did not use concept mapping. However, in Jaafarpour's study, the group mean differences were significant, while they were not significant in our study. It may be 


\section{EFFECT OF CONCEPT MAPPING ON KNOWLEDGE ACQUISITION}

that the larger number of participants in Jaafarpour and colleagues' (2016) study was enough to account for significance, or perhaps there are confounding variations in methods of learning in Iran and the US.

Unlike our assertion that increased post-test and concept map scores demonstrate nursing knowledge acquisition, the findings of other nurse researchers who showed increases in post-test scores and concept map scores after instruction do not explicitly state that this showed a gain in knowledge acquisition (Hsu \& Hsieh, 2005; Jaafarpour et al., 2016). Hsu and Hsieh (2005) stated that students acquired the structure of their knowledge and a skill set for drawing maps without overtly stating they had gains in nursing knowledge. Jaafarpour and colleagues (2016) stated only that concept mapping has a positive effect on academic achievement, without defining what that means or whether nursing knowledge was gained. Despite these differences, this study's findings align with previous studies.

\section{LIMITATIONS}

There are limitations for this study. The study was done at one site and in one course, which limits generalizability. Although $\mathrm{G}$ power indicated a sample size of 34 would be sufficient, and this study had 44 participants whose data was analyzed, it is possible that a larger sample size could have made a difference in significance level. It may also be that limiting the concept mapping instructional session to 30 minutes could have affected students' abilities to really grasp the process, which could have limited the amount of increase in scores. The timing of the posttest, directly after the lecture, may also have affected performance. It may be that students who can effectively use concept mapping to acquire a higher level of knowledge need more time to process the information obtained from the lecture. Using a longitudinal design and conducting a follow-up test later in the semester, as others have done (Jaafarpour et al., 2016; 


\section{EFFECT OF CONCEPT MAPPING ON KNOWLEDGE ACQUISITION}

and Tseng et al., 2011), may have better determined if concept mapping improved knowledge acquisition and retention. Further, although the groups' GPAs were not significantly different, with such a restricted range, it may be that the slightly higher GPA of the control group made a difference in their test-taking ability.

\section{CONCLUSION}

The purpose of this study was to determine if concept mapping improves knowledge acquisition among nursing students. Although the groups' posttest scores were not significantly different, the intervention groups' scores did improve, suggesting an increase in nursing knowledge acquisition. Utilizing concept mapping with lecture, although not found in this study to be better than lecture alone, may be beneficial in increasing nursing conceptual knowledge acquisition. The findings of this study support the use of concept mapping as a helpful learning method for helping students acquire nursing knowledge. Others have found concept mapping to deepen the approach to learning (August-Brady, 2005; Chen et al., 2011; Tseng, et al., 2011), improve clinical care and judgment (Gerdeman, Lux, \& Jacko 2013; Hicks-Moore \& Pastirik, 2006; Taylor \& Wros, 2007), and enhance critical thinking abilities (Atay \& Karabacak, 2012; Chen et al., 2011; Moattari et al., 2014; Samawi et al., 2014; Sinatra-Wilhelm, 2012; Tseng, et al., 2011). This study supports the use of this strategy to help learners acquire the knowledge that may be necessary to pass NCLEX-RN and lay the foundation for competence in nursing practice. Further research is recommended; a focus on longitudinal, multi-site designs with larger sample sizes, and other levels of students could provide stronger evidence for the use of concept mapping in acquisition of nursing knowledge. 


\section{EFFECT OF CONCEPT MAPPING ON KNOWLEDGE ACQUISITION}

\section{REFERENCES}

Ahrin, A. O., \& Corimer, E. (2007). Using deconstruction to educate generation Y nursing students. Journal of Nursing Education, 46(12), 562-567.

Atay, S., \& Karabacak, Ü. (2012). Care plans using concept maps and their effects on the critical thinking dispositions of nursing students. International Journal of Nursing Practice, 18(3), 233-239. Doi:10.1111/j.1440-172X.2012.02034.x

August-Brady, M. M. (2005). The effect of a metacognitive intervention on approach to and selfregulation of learning in baccalaureate nursing students. Journal of Nursing Education, 44(7), 297-304.

Ausubel, D. P. (1963). The psychology of meaningful verbal learning. New York, NY: Grune and Stratton.

Ausubel, D. P. (2000). The acquisition and retention of knowledge: A cognitive view. New York, NY: Springer.

Bixler, G. M., Brown, A., Way, D., Ledford, C., \& Mahan, J. D. (2015). Collaborative concept mapping and critical thinking in fourth-year medical students. Clinical Pediatrics, 54(9), 833-839. doi:10.1177/0009922815590223

Blunt, J. R., \& Karpicke, J. D. (2014). Learning with retrieval-based concept mapping. Journal of Educational Psychology, 106(3), 849-858.

Burrows, N. L., \& Mooring, S. R. (2015). Using concept mapping to uncover students' knowledge structures of chemical bonding concepts. Chemistry Education Research and Practice, 16(1), 53-66. 


\section{EFFECT OF CONCEPT MAPPING ON KNOWLEDGE ACQUISITION}

Cook, L. K., Dover, C., Dickson, M., \& Colton, D. L. (2012). From care plan to concept map: A paradigm shift. Teaching \& Learning in Nursing, 7(3), 88-92. doi: 10.1016/j.teln.2011.11.005

Chen, S., Liang, T., Lee, M., \& Liao, I. (2011) Effects of concept map teaching on students' critical thinking and approach to learning and studying. Journal of Nursing Education, $50(8), 466-9$.

Decker, S., Moore, A., Thal, W., Opton, L., Caballero, S., \& Beasley, M. (2010). Synergistic integration of concept mapping and cause and effect diagramming into simulated experiences. Clinical Simulation in Nursing, 6(4), e153-e159.

Educational Assessments Corporation. (2018). KR(20). Retrieved from https://edassess.net/eacs/kr20.aspx

Felver, L., Gaines, B., Heims, M., Lasater, K., Lausten, G., Lynch, ..., \& Tanner, C. (2010). Best practices in teaching and learning in nursing education. New York, NY: National League for Nursing.

Francis, R. W. (2015). Demonstrating pre-service teacher learning through engagement in global field experiences. Universal Journal of Educational Research, 3(11), 787-792.

Gerdeman, J. L., Lux, K., \& Jacko, J. (2013). Using concept mapping to build clinical judgment skills. Nurse Education in Practice, 13(1), 11-17. doi:10.1016/j.nepr.2012.05.009

Harris, C. M., \& Zha, S. (2017). Concept mapping for critical thinking: Efficacy, timing, \& type. Education, 137(3), 277-280.

Hicks-Moore, S., \& Pastirik, P. (2006). Evaluating critical thinking in clinical concept maps: A pilot study. International Journal of Nursing Education Scholarship, 3(1), 1-15. 


\section{EFFECT OF CONCEPT MAPPING ON KNOWLEDGE ACQUISITION}

Hinck, Webb, Sims-Giddens, Helton, Hope, Utley, ... Yarbrough, S. (2006). Student learning with concept mapping of care plans in community-based education. Journal of Professional Nursing, 22, 23-29.

Hsu, L., \& Hsieh, S. (2005). Concept maps as an assessment tool in a nursing course. Journal of Professional Nursing, 21(3), 141-149.

IBM Corp. (2013). IBM SPSS statistics for windows, Version 22.0. Armonk, NY: IBM Corp.

Jaafarpour, M., Aazami, S., \& Mozafari, M. (2016). Does concept mapping enhance learning outcome of nursing students? Nurse Education Today, 36, 129-132.

doi:10.1016/j.nedt.2015.08.029

Koc, M. (2012). Pedagogical knowledge representation through concept mapping as a study and collaboration tool in teacher education. Australasian Journal of Educational Technology, $28(4), 656-670$.

McClure, J. R., Sonak, B., \& Suen, H. K. (1999). Concept map assessment of classroom learning: Reliability, validity, and logical practicality. Journal of Research in Science Teaching, 36(4), 475-492.

Moattari, M., Soleimani, S., Moghaddam, N. J., \& Mehbodi, F. (2014). Clinical concept mapping: Does it improve discipline-based CT of nursing students. Iranian Journal of Nursing and Midwifery Research, 19(1), 70-76.

Novak, J. D., \& Gowin, D. B. (1984). Learning how to learn. New York, NY: Cambridge University Press.

Peters, M. (2000). Does constructivist epistemology have a place in nurse education? Journal of Nursing Education, 39(4), 166-72. 


\section{EFFECT OF CONCEPT MAPPING ON KNOWLEDGE ACQUISITION}

Polit, D. F., \& Beck, C. T. (2012). Nursing research: Generating and assessing evidence for nursing practice (9th ed.). Philadelphia, PA: Lippincott, Williams, and Wilkins.

Samawi, Z., Miller, T., \& Haras, M. S. (2014). Using high-fidelity simulation and concept mapping to cultivate self-confidence in nursing students. Nursing Education Perspectives, 35(6), 408-409. doi:10.5480/12-1042.1

Sinatra-Wilhelm, T. (2012). Nursing care plans versus concept maps in the enhancement of critical thinking skills in nursing students enrolled in a baccalaureate nursing program. Creative Nursing, 18(2), 78-84.

Taylor, J., \& Wros, P. (2007). Concept mapping: A nursing model for care planning. Journal of Nursing Education, 46(5), 211-216.

Tseng, H., Chou, F., Wang, H., Ko, H., Jian, S., \& Weng, W. (2011). The effectiveness of problem-based learning and concept mapping among Taiwanese registered nursing students. Nurse Education Today, 31, e41-e46. doi: 10.1016/j.nedt.2010.11.020

Vacek, J. E. (2009). Using a conceptual approach with a concept map of psychosis as an exemplar to promote critical thinking. Journal of Nursing Education, 48(1), 49-53.

Veronese, C., Richards, J. B., Pernar, L., Sullivan, A. M., \& Schwartzstein, R. M. (2013). A randomized pilot study of the use of concept maps to enhance problem-based learning among first-year medical students. Medical Teacher, 35(9), e1478-e1484.

doi:10.3109/0142159X.2013.785628

West, D., Park, J., Pomeroy, J., \& Sandoval, J. (2002). Concept mapping assessment in medical education: a comparison of two scoring systems. Medical Education, 36(9), 820-826. 
Table 3

Group Mean Scores, Mean Differences, and Repeated Measures ANOVA

\begin{tabular}{lcc}
\hline & Intervention Group & Control Group \\
\hline Pre-test & 60.08 & 59.92 \\
Post-test & 73.85 & 72.85 \\
Mean Difference & 13.77 & 12.93 \\
RM ANOVA (within subjects) & $F(1,21)=70.816, p<.001$ & $F(1,21)=90.14, p<.001$ \\
Pre-instruction & 26.14 & \\
Post-instruction & 52.32 \\
Mean Difference & 26.18 \\
RM ANOVA (within subjects) & $F(1,21)=37.624, p<.001$ \\
\hline Note: RM ANOVA (between subjects) is non-significant: $F(1)=.080, p=.778$
\end{tabular}




\section{APPENDIX E: ASSIMILATION THEORY CONCEPT MAP}

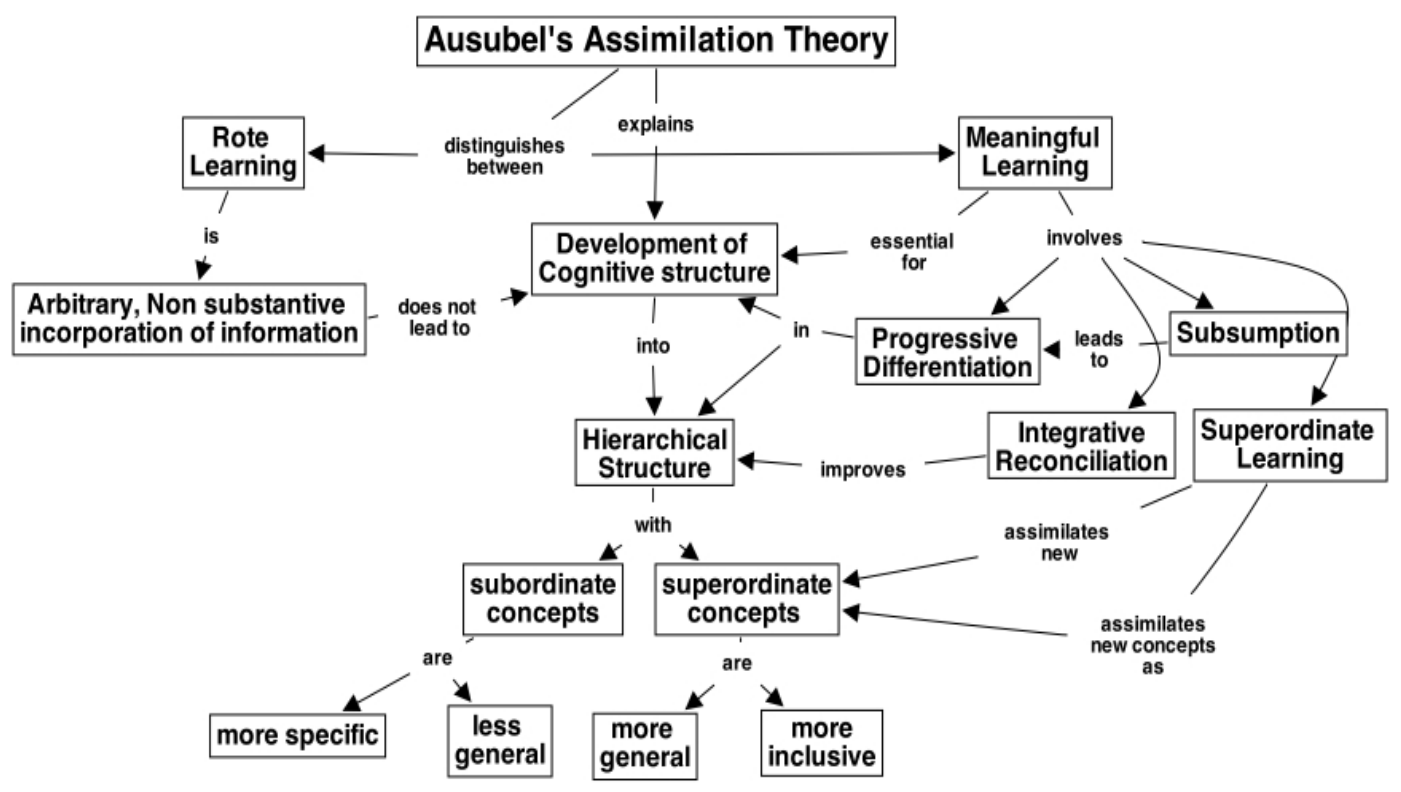

Figure 1. IHMC Cmap Tools. Ausubel's Assimilation Theory. Retrieved from

http://cmapspublic2.ihmc.us/rid=1094487285248_1997460359_5436/ausubel 
EFFECT OF CONCEPT MAPPING ON KNOWLEDGE ACQUISITION

\section{APPENDIX F: STRATEGY FOR INTRODUCING CONCEPT MAPPING}

A. Activities to prepare for concept mapping

11. Make two lists of words on the blackboard or overhead projector using a list of familiar words for objects and another list for events. For example, object words might be car, dog, chair, tree, cloud, book; and event words could be raining, playing, washing, thinking, thunder, birthday party. Ask the students if they can describe how the two lists differ. Try to help them recognize that the first list is things or objects and the second list is happenings or events, and label the two lists

12. Ask the students to describe what they think of when they hear the word car, dog, etc. Help them recognize that even though we use the same words, each of us may think of something a little different. These mental images we have for words are our concepts; introduce the word concept.

13. Repeat the activities in step 2, using event words. Again, point out the differences in our mental images, or concepts, of events. You may want to suggest at this point that one reason we have trouble understanding each other sometimes is that our concepts are never quite identical even though we know the same words. Words are labels for concepts, but each of us must acquire our own meanings for words.

14. Now list words such as are, where, the, is, then, with. Ask students what comes to their minds when they hear each of these words. These are not concept words; we call them linking words and we use them in speaking and writing. Linking words are used together with concept words to construct sentences that have meaning.

15. Proper nouns are not concept words but rather names of specific people, events, places, or objects. Use some examples and help students to see the distinction 


\section{EFFECT OF CONCEPT MAPPING ON KNOWLEDGE ACQUISITION}

between labels for regularities in events or objects and those for specific events or objects (proper nouns).

16. Using two concept words and linking word(s), construct a few short sentences on the board to illustrate how concept words plus linking words are used by humans to convey meanings. Examples would be: The dog is running. Or, There are clouds and thunder.

17. Have students construct a few short sentences of their own, identify the concept words and tell whether each is an object or an event, and also identify the linking words.

18. If you have bilingual students in the class, have them present some foreign words that label the same events or objects. Help the children recognize that language does not make the concept, but only serves as the label we use for the concept.

19. Introduce some short but unfamiliar words to the class such as dire, terse, or canis. These are words that stand for concepts they already know, but have somewhat special meaning. Help students see that meanings of concepts are not rigid and fixed, but can grow and change as we learn more.

20. Choose a section of a textbook (one page is sufficient) and duplicate copies for the children. Choose a passage that conveys a definite message. As a class, ask them to read the passage and identify key concepts. (Usually 10 to 20 relevant concepts can be found in a single page of text material) Also have the students note some linking words and concept words that are less important to the story line.

B. Concept mapping activities 


\section{EFFECT OF CONCEPT MAPPING ON KNOWLEDGE ACQUISITION}

11. Select a particularly meaningful paragraph or two from a text and select the key concepts, that is, those concepts necessary for understanding the meaning of the text. List these concepts on the board (or overhead projector) as they are identified. Now discuss with the students which concept is most important, most inclusive idea in the text.

12. Put the most inclusive concept at the head of a new list of rank-ordered concepts. List the next most-general, most inclusive concepts, working through the first list until all concepts are rank ordered. There will not always be agreement among the students on the ordering, but usually only a few major differences in ranking of concepts will arise. This is OK because it suggests that there may be more than one way to see the meaning of the text.

13. Now begin constructing a concept map, using the rank ordered list a s a guide in building the concept hierarchy. Have students help in choosing good linking words to form propositions [concept-links] shown by lines on the map. One good way to have them practice map making is to have students write concept words and linking words on paper rectangles and then rearrange those rectangles as they get new insights on the map organization.

14. Now look for cross-links between concepts in another part of the concept "tree." Have students help to choose linking words for the cross-links.

15. Most first effort maps have poor symmetry or some concept clusters poorly located relative to other more closely related concepts or clusters of concepts. Reconstruct the map if this would be helpful. Point out to students that at least one and sometimes two 


\section{EFFECT OF CONCEPT MAPPING ON KNOWLEDGE ACQUISITION}

or three reconstructions of a map are needed to show a good representation of propositional meanings as they understand them.

16. Discuss the concept map scoring criteria and score the concept map constructed. Point out possible structural changes that might improve the meaning, and perhaps the score, of the map

17. Have the students select a section of text or other material and repeat steps 1-6 on their own (or in groups of two or three).

18. Student-constructed maps can be presented to the class on the blackboard or overhead projector. "Reading" the map should make clear to other students in the class what the text was about, as interpreted by the map maker.

19. Have students construct a concept map for ideas important in a hobby, sport, or special interest they have. These might be posted around the room and informal discussion encouraged.

20. Incorporate one or two concept mapping questions in your next test to illustrate that concept mapping is a valid evaluation procedure that demands hard thinking and can illustrate understanding of the subject matter.

Note: Adapted from 'Strategies for introducing concept mapping in grades seven through college', in Novak, J. D., \& Gowin, D. B. (1984). Learning how to learn. New York, NY: Cambridge University Press, p.p. 32-34. (Blanket permission granted by authors in text.) 


\section{APPENDIX G: CONCEPT MAPPING STRUCTURAL SCORING METHOD}

\section{Scoring Criteria}

6. Concept-link:

Is the meaning relationship between two concepts indicated by a connecting line/arrow and linking word(s)? Is the relationship valid? If yes, score 1 point for each valid concept-link.

7. Hierarchy:

Does the map show hierarchy? Is each subordinate concept more specific and less general than the concept shown above it (in the context of the material being mapped)? If yes, score 5 points for each valid level of hierarchy.

8. Cross-links:

Does the map show meaningful connections between one segment of the concept hierarchy and another segment? Is the relationship shown significant and valid? If yes, score 10 points for each cross-link that is both significant and valid.

9. Examples:

Score 1 point each for specific events or objects that are valid instances of those designated by the concept label.

10. Invalid Components:

Inclusion of invalid components in the concept map receive zero (0) points.

\section{Scores}

Concept-links: $\quad$ Number of valid concept-links $\quad$ Number of valid hierarchy levels $\ldots 1=$
Hierarchy:
Cross-links: Number of valid \& significant cross links __

\section{Structural Score:}

(Total points) 


\section{APPENDIX H: MENTAL STATUS PRETEST/POSTTEST}

1. Mental status is best defined as:

A. The temporary expression of feeling or state of mind

B. Prolonged display of feelings that color the emotional life

C. The awareness of the objective world in relation to self

D. A person's emotional and cognitive functioning

2. Mental disorder is best defined as:
A. Brain disease of specific, known organic cause
B. Syndromes in which there is no known organic cause
C. Morbid worry about one's health with no known basis in fact
D. Significant behavioral or psychological pattern associated with distress or disability

3. Mental status is assessed by inference through assessment of an individual's:
A. vital signs
B. behaviors
C. intelligence
D. level of depression

4. The Level of Consciousness in which an individual groans, moves restlessly, and responds only to persistent and vigorous stimulation is called:
A. Lethargy
B. Obtunded
C. Stupor
D. Coma

5. When assessing mental status of an older adult, the nurse knows:
A. The parameters of mental status are no longer intact
B. There is a decrease in general knowledge
C. There is a substantial loss of vocabulary
D. The response time is slower

6. When a patient has been in the ICU for 10 days and just moved to the medical floor, the nurse can expect which one of the following when testing cognitive function? The patient:

A. May display some disruption in thought content

B. Will state, "I am so relieved to be out of intensive care"

C. Will be oriented to person and place but may not be certain of the date Show evidence of some clouding of his level of consciousness

7. A patient has been diagnosed with Schizophrenia. When assessing mental status, the nurse can expect which one of the following? 

A. Flat (blunted) affect
B. Labile affect
C. Depressed mood
D. Elated mood

8. A patient was doing well yesterday, but seems sad today. How would the nurse assess the patient's mood?
A. Observe the patient's facial expression
B. Assess the patient's body language
C. Ask the patient about his/her mood
D. Determine the patient's level of orientation

9. When the nurse asks the patient how his evening was, the patient tells the nurse that he enjoyed the night out playing bridge with friends last evening. However, the nurse knows the patient was in the hospital. This abnormality of thought process is:
A. Circumlocution
B. Confabulation
C. Loose Associations
D. Circumstantiality

10. A patient stands up during a group meeting and exclaims, "I am God, bow down before me and repent!" This abnormality of thought content is a/an:
A. Obsession
B. Illusion
C. Hallucination
D. Delusion of grandeur

11. A patient is sitting alone and starts holding his ears and yells, "Shut up, stop telling me that!" then there is a pause and he yells "My mom is not bad, leave me alone!" This abnormality in perception is a/an:
A. Obsession
B. Illusion
C. Hallucination
D. Delusion of grandeur

12. When assessing memory of an older adult who can't remember what she had for breakfast, but her long-term memory is intact, the nurse knows that this:
A. Is very common in older adults
B. May be a sign of Generalized Anxiety Disorder
C. May be a sign of Amnesic Disorder
D. Cannot be an early sign of Dementia 
13. The Four Unrelated Words Test can be used to assess capacity for new learning. The normal response for those under age 60 should be the ability to:
A. Recall the general time and location
B. Recall the precise date and location
C. Recall 3 out of 4 words after 10 minute delay
D. Recall 4 out of 4 words after 30 minute delay

14. Which one of the following is true about the Mini Mental State Examination? It:
A. Contains 30 questions and requires less than an hour to conduct
B. Is useful as initial screening tool, but should not be used for serial evaluations
C. Detects organic problems, like delirium and dementia
D. Concentrates on mood and thought processes only, not cognition

15. When assessing the mental status of a child, the nurse must know and consider:
A. Whether the child is coping well in his/her environment
B. Whether the child is an only child
C. Whether the parents are overly involved
D. Whether the child is meeting developmental milestones

Last 4 digits of cell phone:

Gender (Biological Sex) (circle one): $\quad$ Male $\quad$ Female

Age:

Prior experience with concept mapping (check one)? Yes ___ No __

GPA: 